\title{
Kalite Kontrol Grafiklerinde R Programlama Dilinin Kullanımı İle İlgili İçerik Analizi ${ }^{1}$
}

\author{
DOI: $10.26466 /$ opus.589423 \\ *
}

$\underline{\text { Kenan Orçanl1* }}$

\author{
* Öğr.Gör.Dr., Milli Savunma Üniversitesi, Kara Harp Okulu, Ankara. \\ E-Posta: kenanorcanli@gmail.com $\quad$ ORCID: $\underline{\text { 0000-0001-5716-4004 }}$
}

\section{Öz}

İstatistiksel süreç kontrolünde kalite iyileştirmeye yardımcı olan çeşitli yöntemler bulunmasına rağmen, kalite kontrol grafikleri mevcut yöntemlerin en önemlisi olarak kabul edilir. Bu grafiklerin diğer yöntemlere göre üstün taraflar tasarlanmasının, kullanımının ve görsel olarak anlaşılmasının kolay olmasıdır. Kalite kontrol grafiklerinde belirlenen kalite karakteristikleri ile ilgili gözlemler, genellikle SPSS, MINITAB, STATA gibi hazır paket programlarında ya da MATLAB, C++ gibi programlama dilleri ile oluşturulan grafiklerde takip edilmektedir. Ancak son zamanlarda R programlama dilinin de kalite kontrol grafiklerinin oluşturulmasında, kontrol dışı sinyallerin tespiti ile hata teşhisinde ve benzeri alanlarda kullanımının hızla yaygınlaştığı ve yabancı literatürde oldukça fazla çalışmanın yapıldı̆̆ı tespit edilmiştir. Bu kapsamda, R programlama dilinin kalite kontrol grafiklerinde kullanımı ile ilgili olarak içerik analizi yöntemi kullanılarak bir araştırma yapılmasına ihtiyaç duyulmuştur. Bu amaçla yapılan çalışmanın, kalite kontrolünde çalışanlar ile yerli ve yabancı literatüre katkı sağlayacă̆l değerlendirilmektedir. Yapılan çalışmada; dört adet kitap ve 36 adet makale, içerik analizi yöntemi kapsaminda yedi ölçüte göre oluşturulan araştırma ölçeğine uygun olarak incelenmiştir. Çalışmanın sonucunda; (1) $R$ programlama dilinin kontrol grafiklerinde kullanımı ile ilgili olarak incelenen kitaplarda ve makalelerde teorik konulara ağırlık verildiği, uygulamal konularm azınlıkta olduğu, (2) kalite kontrol grafiklerinin dizayn edilmesinde en çok $R$ paketlerinden "qcc" paketinin kullanıldığı, ancak diğer paketlerden de ihtiyaç duyulan fonksiyonların kullanıldı̆̆g, (3) yapılan uygulamalar ile teori geliştirmede ağırlıklı olarak çok değişkenli kontrol grafiklerinin kullanıldığı ve kullanilan kontrol grafiklerinden ise en çok Hotelling $T^{2}$, MCUSUM ve MEWMA kontrol grafikleri ile uygulamalarm yapıldı $\breve{g}$, (4) kontrol grafiklerinin performansının ölçülmesinde ve performanslarının karşılaştırılmasında ARL değerlerinin kullanıldığı, (5) kontrol grafikleri ile yapılan uygulamalarda ă̆ırlıkl olarak yapay verilerin kullanıldı̆̆ çalı̧malarında Monte Carlo simülasyon yönteminin tercih edidiği ve (7) çeşitli durumlar için önerilen çok çeşitli kontrol grafiğinin literetürde yer aldığı sonuucuna ulaşılmıştır.

Anahtar Kelimeler: $\quad$ R Programlama Dili, Kontrol Grafikleri, Kalite Kontrolü

\footnotetext{
1 Bu çalışma, 12-14 Haziran 2019 tarihleri arasında Başkent Üniversitesi (Ankara)'da düzenlenen 38. Yöneylem Araştırması ve Endüstri Mühendisliği Ulusal Kongresinde sözlü olarak sunulan ve kongre kitabında özet metin olarak yayımlanan metnin, gelen eleştiriler ve öneriler doğrultusunda geliştirilmiş halidir.
} 


\title{
Content Analysis about Usage of $\mathbf{R}$ Programming Language in Quality Control Charts
}

\begin{abstract}
Although there are various methods that help improve quality in statistical process control, quality control charts are considered to be the most important methods available. The superiority of these charts compared to other methods is that they are easy to use, to design and visually understandable. Observations related to the quality characteristics determined in the quality control charts are generally followed by the creation of package programs such as SPSS, MINITAB, STATA or programming languages such as MATLAB, C++. Recently, however, it has been determined that the use of $R$ programs in the creation of quality control charts, the detection of uncontrolled signals in these charts, in the diagnosis of errors and similar areas is rapidly becoming widespread and a lot of studies are conducted in foreign literature. In this context, it was aimed to make a research about the use of $R$ program in quality control charts. In this way, it is considered that this study will contribute to the quality control employees and the domestic and foreign literature. In this study, four books and thirty-six articles were examined according to content analysis method according to seven criteria. As a result of the study; (1) in the books and articles examined in relation to the use of the $R$ program in control charts, theoretical issues are emphasized, applied issues are in the minority, (2) most of the $R$ packages used in the design of quality control charts is qcc package (3) mainly used control graphs are multivariate control graphs in theory development and applications, and most commonly used control charts were Hotelling $T^{2}$, MCUSUM and MEWMA control charts, and (4) control charts were measured using ARL. (5) mainly used artificial data in applications with control charts, (6) Monte Carlo simulation method is preferred in simulation studies, (7) it is concluded that a wide variety of control charts suggested for various situations are included in the literature.
\end{abstract}

Keywords: $\quad$ R Programming Language, Control Charts, Quality Control 


\section{Giriş}

Günümüzde hızlı ve sürekli olarak değişen çevre, işletmeleri de çeşitli düzeylerde ve şekillerde etkilemekte olup, onları değişime zorlamaktadır. Bu kapsamda işletmeler varlıklarını sürdürebilmek maksadıyla dış çevrelerindeki değişikleri önceden tahmin etmek ve yüksek rekabet ortamına rakiplerine karşı üstünlük sağlamak zorundadır. İşletmelerin rakiplerine karşı üstünlük sağlayabilmeleri için çeşitli rekabet araçları bulunmaktadır. Bu rekabet araçlarından birisi de kalitedir.

Kalite kavramı, günümüzde hayatımızın her aşamasında karşı karşıya kaldığımız önemli kavramlar arasındadır. Yerli ve yabancı literatürde kalite kavramı ile ilgili olarak J.M. Juran, P.B. Crosby, W.E. Deming, A.V. Feigenbaum, G.Taguchi ve K.Ishikawa gibi kalite öncüleri ile Avrupa ve Amerikan Kalite Kontrol Organizasyonları, Japon Sanayi Standartları Komitesi ve Türk Standartları Enstitüsü gibi kaliteden sorumlu kuruluşlar tarafından (Birgören, 2015; Orçanll, 2017) aynı amaca hizmet eden ve birbirine benzer birçok tanım yapılmıştır. Yapılan tanımlar incelendiğinde; kalite kavramının standart bir tanımının olmadığ görülmektedir. Kalite, bir mal veya hizmetle ilgili olabileceği gibi, müşteri gereksinim ve istekleri ile de ilgili olabilecek bir kavramdır. Standart bir tanımının bulunmaması nedeni ise kalitenin kullanıcı gereksinim ve beklentileri ile olan doğrudan ilgisi ve bu gereksinim ve beklentilerin devamlı olarak değişiminden kaynaklanmaktadır (Orçanlı, 2017).

İşletmelerde, belirli standartlara bağlanmış kaliteli mal ve hizmet üretimi, etkin bir kalite kontrolü ile mümkündür. Bu nedenle işletmeler organizasyonunda gerekli değişimleri yaparak kontrolü sistemleştirmek zorundadır. Kalite, iç ve dış müşterilerin ihtiyaçlarını karşılayacak mal ve hizmetlerin özelliklerin tümü olduğu farz ve kabul edilecek olunursa, kalite kontrolü de bu özelliklerin oluşturulmasını sağlayacak süreçler, faaliyetler ve yöntemlerin toplamı (Öztürk, 2009) olarak tanımlanabilir. Dolayısıyla kalite ve kalite kontrolü birbirinden ayrılmaz iki kavram olarak karşımıza çıkar.

Kalite kontrolü, genel olarak üç alandan oluşmaktadır. Bunlar sırasıyla istatistiksel süreç kontrolü, kabul örneklemesi ve deney tasarımıdır. Söz konusu kavramların hepsi önemli de olsa, istatistiksel süreç kontrolü diğerlerine göre daha fazla ön plana çıkmaktadır (Birgören, 2015). 
İstatistiksel süreç kontrolü, Türkçe literatürde istatistiksel proses kontrolü, istatistiksel süreç kontrolü gibi çeşitli isimlerle anılmaktadır. İstatistiksel süreç kontrolü, herhangi bir sürecin çıktısını veya değişkenliğini ölçmek ve analiz etmek için kullanılan bir yöntemdir (Işığıçok, 2012). Söz konusu yöntem, süreç yeterliliğini değerlendirmede, kronik kalite sorunlarını çözmede, sorunların temel nedenlerini bulmada süreç iyileştirme ve geliştirme faaliyetlerinde kullanılır (Öztürk, 2009). İstatistiksel süreç kontrolünde belirtilen amaçları gerçekleştirmek için pareto diyagramı, neden-sonuç diyagramı, tabakalama analizi, kontrol listeleri, beyin fırtınası gibi çeşitli araçların bulunmasına rağmen en yaygın kullanılan araç, kalite kontrol grafikleridir (Birgören, 2015). Kalite kontrol grafikleri, ürünün gerçek kalite spesifikasyonlarını öncesinden deneyimler sonucu toplanan ölçümlere göre belirlenen sinırlara göre karşılaştırmaya yarayan grafiklerdir (Öztürk, 2009). Kalite kontrol grafikleri, herhangi bir süreçteki sorunları gösterebilirken, aynı zamanda tespit edilen sorunlar hakkında ipuçları verebilir. Dolayısıyla kalite kontrol grafikleri, sürecin sesi olup, sürecin istikrarlı bir şekilde çalışıp çalışmadığı konusunda bilgi de verir. Literatürde süreç değişiminin kontrolünü sağlayan kalite kontrol grafiklerinin çok farklı türü olmasına rağmen, ölçülebilen değerleri kullanmaları yönünden temelde iki türü bulunmaktadır. Ölçülebilen değerleri kullanan kalite kontrol grafiklerine örnek olarak tek değişkenli $X, R, E W M A, C U S U M$ ve önerilen tek değişkenli diğer kalite kontrol grafikleri ile çok değişkenli Hotelling $T^{2}, M E W M A$, CUSUM ve önerilen çok değişkenli diğer kontrol grafikleri verilebilir. $\mathrm{Bu}$ kalite kontrol grafiklerini temel alıp literatürde birçok kalite kontrol grafiği de önerilmiştir. Ayrıca ölçülebilen kalite karakteristiklerinin yanı sıra özelliklerden, sayısal olarak ölçülemeyen ancak bulanık gözlem değerlerinden oluşan kalite karakteristiklerini izleyen çeşitli türde kontrol grafikleri de literatürde yer almaktadır.

Kalite kontrol grafikleri, bir süreçten düzenli gözlemler alınması ve bu ölçüm değerlerinin ya da bu ölçüm değerlerinden ortalama veya buna benzer bazı istatistik değerlerinin zamana göre grafiğinin çizilmesiyle oluşturulur (Birgören, 2015). Uygulamada kritik kalite karakteristikleri kullanılır ve üretimin belli aşamalarında örneklemler alınarak ölçümler yapılır. Ölçümlerin kalite kontrol grafiklerine aktarılarak sürecin kontrol altında olup olmadığı kontrol edilir. Anlatılan yöntem, kalite kontrol 
grafiklerinin dizayn edilmesinde uygulanan en genel kalite kontrol grafiğinin oluşturulma şeklidir. İleri seviyede kalite kontrol grafiklerinin oluşturulmasında ise daha karmaşık yöntemler uygulanmaktadır. Dolayısıyla kalite kontrol grafiklerinin oluşturulması ve daha iyi anlaşılması için görsel olarak dizayn edilmesinde çeşitli hesaplama araçlarının kullanılmasına ihtiyaç duyulmaktadır. Bu ihtiyacın giderilmesinde hem literatürde yapılan akademik çalışmalarda hem de endüstride uygulama alanlarında MINITAB, SPSS, STATA, SAS, Julia, Python gibi çeşitli bilgisayar programları ile programlama dilleri de kullanılmaktadır. Ancak son zamanlarda dünyada ve Türkiye'de oldukça yaygın olarak kullanılmaya başlanan $\mathrm{R}$ programlama dili de kalite kontrol grafiklerinin oluşturulmakta kullanılmaktadır. R programlama dili, açık kaynak kodlu ve ücretsiz bir programlama dilidir (Satman, 2018). R programlama dili, son yıllarda giderek yaygınlaşmakta olan bir dil olmakla beraber ülkemizde henüz akademik alanda dahi kullanımı kısıtlı seviyededir. Diğer yandan dünyada bu dilin kullanımı gittikçe hızlanarak artmaktadır. Dolayısıyla R programlama dilinin kullanıldığı alanlarda araştırma yapmak araştırmacılara birçok faydalar sağlamaktadır. Bu kapsamda yapılan çalışmanın amac1; kalite geliştirme ve iyileştirme çabaları kapsamında, $\mathrm{R}$ programlama dilinin kalite kontrol grafiklerinde kullanım şeklini ve seviyesini ortaya koymak ile nasıl bir gelişme gösterdiğini tespit etmek, gelecek dönemlerde $\mathrm{R}$ programlama dilinin kontrol grafiklerinin dizayn edilmesinde etkili bir şekilde nasıl oluşturulabileceği ile ilgili öngörülerde ve önerilerde bulunmak, literatürde belirtilen konu ile ilgili bir boşluğu doldurmak ve yeni başlayan araştırmacılar için bir başlangıç noktası olmasını sağlamaktır.

\section{R Programlama Dili}

Günümüzde tüm dünyada veri biliminde kullanılan açık kaynak kodlu, ücretsiz ve başvuru kaynakları çok olan programlama dillerinin önemi her geçen gün giderek artmaktadır. Bu programlama dillerinden birisi de $\mathrm{R}$ programlama dilidir.

İstatistik hesaplama için kullanılan açık kaynak kodlu R programlama dili, özellikle istatistiksel çalışmalar için tasarlanmış bir programlama dili ve ortamıdır. Bu programlama dili, 1996 yılında Yeni Zelanda'da Aucland 
Üniversitesi'nde görevli Ross Ihaka ve Robert Gentleman tarafından geliştirilmiştir. Ancak programlama dilinin temeli, 1960'lı yıllarda Bell Labratories'de John Chambers ve arkadaşları tarafından geliştirilen S programlama diline dayanmaktadır. Daha sonra dünyanın çeşitli yerlerindeki araştırmacılar $\mathrm{R}$ programlama dilini geliştirmek için bir araya gelmiş ve 1997 yılında bu gruba "R Core Team" adı verilmiştir (Arslan, 2017).

$\mathrm{R}$ programlama dilinin birçok kullanım alanı bulunmaktadır. R programlama dili, özellikle her türlü ekonometrik ve istatistik çalı̧̧manın yanı sıra veri madenciliği, makine öğrenmesi ile yapay sinir ağları, büyük veri analizi, ağ analizi, nesneye dayalı programlama, simülasyon uygulamaları, kalite kontrol gibi birçok alanda kullanım imkanı sunmaktadır. $\mathrm{R}$ programlama dili bu özellikleri ile gerek iş dünyasında gerekse akademik çevrelerde veri analitiği çalışmalarında kullanılan esnek ve güçlü bir programlama dilidir (Satman, 2018).

R programlama dili, diğer birçok özelliğin yanı sıra veri manipülasyonu, programlama ve grafiksel gösterimi bir arada sunan entegre bir yazılım programıdır (Arslan, 2017). Dolayısıyla bu özelliği ile birlikte R programlama dili kalite kontrol grafiklerinde kullanılabilecek en uygun bir programlama dilidir. Bu kapsamda gelecek ylllarda $\mathrm{R}$ programlama dilinin kalite kontrol grafikleri ile yapılacak uygulamalarda artarak kullanılacağı değerlendirilebilir.

Kalite kontrol grafikleri ile ilgili olarak yapılan çalışmalarda kullanılmak üzere $R$ programlama dilinde araştırmacılar tarafından oluşturulmuş birçok R paketi bulunmaktadır. İnternet ortamında yapılan inceleme neticesinde kalite kontrol grafiklerinde kullanılan $\mathrm{R}$ programlama dili paketleri Tablo-1'de yer verilmiştir.

\section{Tablo-1. R Programında Kullanılan Kalite Kontrol Grafikleri Paketleri}

\begin{tabular}{|c|c|c|c|}
\hline $\begin{array}{c}\text { S. } \\
\text { No }\end{array}$ & R Paketi & Zaman & Kullanım Amacı \\
\hline 1 & qcc & 2004 & $\begin{array}{l}\text { qcc (quality control charting) paketi, ölçülebilen, özellikli ve sürekli ve- } \\
\text { riler için dizayn edilmiş Shewhart, EWMA ve CUSUM kontrol gra- } \\
\text { fikleri, süreç yeterliği, Pareto ve neden-sonuç grafiğinin oluşturul- } \\
\text { ması için tasarlanmiş bir R paketidir. }\end{array}$ \\
\hline 2 & spc & 2013 & $\begin{array}{l}\text { spc (statistical process control - calculation of ARL and other control chart } \\
\text { performance measures) paketi, EWMA ve CUSUM kontrol grafiklerini } \\
\text { baz alarak oluşturulan çeşitli kontrol grafiklerinin çeşitli senaryolar }\end{array}$ \\
\hline
\end{tabular}




\begin{tabular}{|c|c|c|c|}
\hline & & & $\begin{array}{l}\text { kapsamında } A R L \text { değerlerinin hesaplanması için fonksiyonlar oluş- } \\
\text { turulması maksadıyla hazırlanmış bir } \mathrm{R} \text { paketidir. }\end{array}$ \\
\hline 3 & MSQC & 2013 & $\begin{array}{l}\text { MSQC (multivariate statistical quality control) paketi, Hotelling, Chi } \\
\text { kare, MEWMA, MCUSUM ve genelleştirilmiş kontrol grafiği, çok de- } \\
\text { ğişkenli normallik testi (Mardia, Royston ve Henze Zirkler test), tek } \\
\text { değişkenli normallik testi (D'Agostino test) için oluşturulmuştur. }\end{array}$ \\
\hline 4 & edcc & 2015 & $\begin{array}{l}\text { edcc (the economic design of the control chart) paketi, Xbar, EWMA ve } \\
\text { CUSUM kontrol grafiklerinin ekonomik dizaynı için oluşturulmuş- } \\
\text { tur. }\end{array}$ \\
\hline 5 & QCGWAS & 2015 & $\begin{array}{l}\text { QCGWAS (quality control of genome wide association study results) pa- } \\
\text { keti, genetik varyasyonları tanımlamak ve bu amaçla SNP gibi var- } \\
\text { yasyonların ilişkili belirteçlerini araştırmada hasta ve kontrol grup- } \\
\text { larının bütün genomlarının analiz edilmesini içeren çalışmaların ka- } \\
\text { lite kontrol çalışmalarının tespiti amacıyla oluşturulmuş bir R pake- } \\
\text { tidir. }\end{array}$ \\
\hline 6 & $\begin{array}{l}\text { CMP } \\
\text { Control }\end{array}$ & 2015 & $\begin{array}{l}\text { CMPControl (control charts for Conway-Maxwell-Poisson distribution) } \\
\text { paketi, klasik poisson dağılımına sahip veriler için oluşturulmuş } \\
\text { kontrol grafiği ile Conway-Maxwell-Poisson dağıllmına sahip veriler } \\
\text { için oluşturulmuş kontrol grafiğinin karşışaştırılması ve söz konusu } \\
\text { kontrol grafiğinin parametrelerinin hesaplanabilmesi için oluşturul- } \\
\text { muş bir R paketidir. }\end{array}$ \\
\hline 7 & $\begin{array}{l}\text { process } \\
\text { control }\end{array}$ & 2016 & $\begin{array}{l}\text { processcontrol (statistical process control charts) paketi, IndX ve } m R \\
\text { kontrol grafiklerinin dizaynı ve bu kontrol grafiklerinde zaman serisi } \\
\text { verilerinin kullanımı ile ilgili yapılan bir R paketidir. }\end{array}$ \\
\hline 8 & $\begin{array}{l}\text { CUSUM } \\
\text { design }\end{array}$ & 2016 & $\begin{array}{l}\text { CUSUMdesign (compute decision interval and ARL for CUSUM charts) } \\
\text { paketi, CUSUM kontrol grafiğinin ARL değerleri ile kontrol sinırları- } \\
\text { nın oluşturulmasının hesaplanması ile ilgili olarak yapılan bir R pa- } \\
\text { ketidir. }\end{array}$ \\
\hline 9 & qcr & 2016 & $\begin{array}{l}\text { qcr paketi, Xbar, Xbar-one, } S, R, E W M A, C U S U M, M E W M A, M C U- \\
S U M \text { ve } T^{2} \text { kontrol grafikleri, nonparametrik çok değişkenli kontrol } \\
\text { grafikleri, parametrik ve nonparametrik proses yeterlik analizi için } \\
\text { oluşturulmuştur. }\end{array}$ \\
\hline 10 & spcadjust & 2016 & $\begin{array}{l}\text { spcadjust (functions for calibrating control charts) paketi, kontrol gra- } \\
\text { fiklerinde tahmin hatalarını düzenlemek amacıyla ihtiyaç duyulan } \\
\text { formüllerin oluşturulması amacıyla yapılan bir R paketidir. }\end{array}$ \\
\hline 11 & graphicsQC & 2016 & $\begin{array}{l}\text { graphicsQC paketi, halen literatürde mevcut olan kontrol grafikleri- } \\
\text { nin dizaynını geliştirmek amacıyla oluşturulmuştur. }\end{array}$ \\
\hline 12 & attrCUSUM & 2016 & $\begin{array}{l}\text { attrCUSUM (tools for attribute Vsı CUSUM control chart) paketi, CU- } \\
\text { SUM kontrol grafiğinin poisson dağılımına sahip özellikli veriler için } \\
\text { dizayn edilmesi için gerekli olan formüllerin yer aldığı bir R paketi- } \\
\text { dir. }\end{array}$ \\
\hline
\end{tabular}




\begin{tabular}{|c|c|c|c|}
\hline 13 & XRSCC & 2016 & $\begin{array}{l}\text { XRSCC (Statistical Quality Control Simulation) paketi, kontrol grafik- } \\
\text { lerinin oluşturulması ile ölçülebilen değişkenler ve özellikli değiş- } \\
\text { kenler için süreç yeterliliğinin hesaplanması amacıyla ihtiyaç duyu- } \\
\text { lan fonksiyonların yer aldığı bir R paketidir. }\end{array}$ \\
\hline 14 & IQCC & 2017 & $\begin{array}{l}\text { IQCC (improved quality control charts) paketi, tek ve çok değişkenli } \\
\text { kontrol grafiklerinde kontrol limitlerinin hesaplanması için gerekli } \\
\text { olan formüllerin yer aldığ bir R paketidir. }\end{array}$ \\
\hline 15 & qcc & 2017 & $\begin{array}{l}\text { qcc (quality control charting) paketi, Shewhart (sürekli ve özellikler), } \\
\text { CUSUM ve EWMA kontrol grafikleri, süreç yeterlilik analizi, Pareto } \\
\text { ve cause-and-effect diyagramı, çok değişkenli } \mathrm{T}^{2} \text { kontrol grafiğinin } \\
\text { dizaynı için oluşturulmuştur. }\end{array}$ \\
\hline 16 & qicharts & 2017 & $\begin{array}{l}\text { qicharts (quality improvement charts) paketinde, kalite gelişme çaba- } \\
\text { ları kapsamında Pareto kontrol grafiğinin dizaynı ve Shewhart kont- } \\
\text { rol grafiği için oluşturulmuş bazı fonksiyonlar yer almaktadır. }\end{array}$ \\
\hline 17 & dfphase1 & 2017 & $\begin{array}{l}\text { dfphase1Phase I (Control Charts with Emphasis on Distribution-Free } \\
\text { Methods) paketi, normal dağılmayan veriler için Faz I aşamasında di- } \\
\text { zayn edilmesi gereken önerilen çeşitli sağlam kontrol grafiklerinin } \\
\text { yer aldığı bir R paketidir. }\end{array}$ \\
\hline 18 & $\begin{array}{l}\text { Energy } \\
\text { Online } \\
\text { CPM }\end{array}$ & 2017 & $\begin{array}{l}\text { EnergyOnlineCPM (distribution free multivariate control chart based on } \\
\text { energy test) paketi, normal dağılmayan veriler için dizayn edilen çok } \\
\text { değişkenli kontrol grafiklerinde meydana gelen yapısal değişimlerin } \\
\text { tespiti için önerilen bir adet fonksiyonun yer aldığı bir R paketidir. }\end{array}$ \\
\hline 19 & PsyControl & 2017 & $\begin{array}{l}\text { PsyControl (CUSUM person fit statistics) paketi, CUSUM kontrol gra- } \\
\text { fiklerine dayalı olarak özelleştirilmiş bireysel istatistiklere dayalı bir } \\
\text { R paketidir. }\end{array}$ \\
\hline 20 & ggQC & 2018 & $\begin{array}{l}\text { ggQC paketi, } R, X m R, c, n p, p, u, x \text { Bar.rBar, } x \text { Bar.rMedian, } x \text { Bar.sBar, } \\
x \text { Median.rBar, } x \text { Median.rMedian, } r \text { Bar, } r \text { Median, sBar kontrol grafikle- } \\
\text { rinin dizayn, Pareto, süreç yeterlilik analizi ve Shewart violation } \\
\text { analizi için oluşturulmuştur. }\end{array}$ \\
\hline 21 & vlad & 2018 & $\begin{array}{l}\text { vlad (variable life adjusted display and other risk-adjusted quality control } \\
\text { charts) paketi, sağlık alanında meydana gelen riskli durumların tes- } \\
\text { piti için CUSUM kontrol grafik tabanlı oluşturulmuş fonksiyonları } \\
\text { kapsayan bir R paketidir. }\end{array}$ \\
\hline 22 & qccrs & 2018 & $\begin{array}{l}\text { qccrs (quality control charts under repetitive sampling) paketi, tekrarlı } \\
\text { örneklemler ile kurulan kontrol grafiklerin oluşturulması ile ARL ve } \\
\text { ortalama örneklem sayısının hesaplanması konusunda gerekli fonk- } \\
\text { siyonların yer aldığı bir R paketidir. }\end{array}$ \\
\hline 23 & qicharts2 & 2018 & $\begin{array}{l}\text { qicharts2 (quality improvement charts-2) paketi, süreçten veya ürün- } \\
\text { den alınan örneklemlerdeki sürekli verileri kullanılarak yapılması } \\
\text { planlanan kalite geliştirme çabalarının desteklenmesi amacıyla oluş- } \\
\text { turulmuştur. }\end{array}$ \\
\hline 24 & Rspc & 2018 & $\begin{array}{l}\text { Rspc (nelson rules for control charts) paketi, } I \text { kontrol grafiğinin Levey- } \\
\text { Jennings tipi, Shewhart } C \text { kontrol grafiği ve Nelson kurallarının }\end{array}$ \\
\hline
\end{tabular}




\begin{tabular}{|c|c|c|c|}
\hline & & & $\begin{array}{l}\text { geliştirilmesi ile ilgili olarak gerekli fonksiyonların yer aldığı bir } \mathrm{R} \\
\text { paketidir. }\end{array}$ \\
\hline 25 & vMask & 2018 & $\begin{array}{l}\text { vMask (detect small changes in process mean using CUSUM control chart } \\
\text { by v-mask) paketi, V-mask yardımı ile dizayn edilen CUSUM kontrol } \\
\text { grafiğinin kullanılarak ufak değişimlerin tespit edilmesi için gerekli } \\
\text { fonksiyonların yer aldığı bir R paketidir. }\end{array}$ \\
\hline 26 & weco & 2018 & $\begin{array}{l}\text { weco (western electric company rules (WECO) for shewhart control chart) } \\
\text { paketi, Shewhart kontrol grafiklerinde belirlenen kontrol grafiklerin- } \\
\text { deki kontrol dişı durumların yorumlanması ile ilgili olarak oluştu- } \\
\text { rulmuş fonksiyonların yer aldığı bir R paketidir. }\end{array}$ \\
\hline 27 & xmrr & 2018 & $\begin{array}{l}\text { xmrr (generate XMR control chart data from time-series data) paketi, za- } \\
\text { man serisi gözlem değerlerinin izlenmesi maksadıyla } X \text { ve } M R \text { kont- } \\
\text { rol grafiklerinin birleştirilmesi ile oluşturulan } X M R \text { kontrol grafiği- } \\
\text { nin dizayn edilmesi için gerekli olan fonksiyonların yer aldığ bir R } \\
\text { paketidir. }\end{array}$ \\
\hline 28 & PlinkQC & 2019 & $\begin{array}{l}\text { PlinkQC (genotype quality control with 'Plink') paketi, genetik verile- } \\
\text { rinin kalitesinin izlenmesi maksadiyla oluşturulmuş bir R paketidir. }\end{array}$ \\
\hline 29 & surveillance & 2019 & $\begin{array}{l}\text { surveillance paketi, zaman serilerinin izlenmesi ve CUSUM kontrol } \\
\text { grafiği için gerekli bazı özel fonksiyonların yer aldığı bir R paketidir. }\end{array}$ \\
\hline 30 & fastqcr & 2019 & $\begin{array}{l}\text { fastqcr paketi, çoklu örneklemlerde QC raporunun oluşturulabilme- } \\
\text { sinde kullanılmak üzere sıralı kalite kontrol grafikleri (tek örneklem } \\
\text { QC raporu } \\
\text { (+ yorumlama), çoklu örneklem QC raporu (yorumlama yok)) için } \\
\text { oluşturulmuştur. }\end{array}$ \\
\hline 31 & cusum & 2019 & $\begin{array}{l}\text { cusum (CUSUM charts for monitoring of hospital performance) paketi, } \\
\text { sağllk alanında hastanelerin performans göstergelerinin CUSUM } \\
\text { kontrol grafikleri ile izlenmesi amaciyla oluşturulmuş bir R paketi- } \\
\text { dir. }\end{array}$ \\
\hline 32 & npcp & 2019 & $\begin{array}{l}\text { npcp (some nonparametric CUSUM tests for change-point detection in } \\
\text { possibly multivariate observations) paketi, çok değişkenli ortamlarda } \\
\text { yapısal kırılımları tespit etmek amacıyla parametrik olmayan } C U \text { - } \\
\text { SUM testlerini kapsayan bir R paketidir. }\end{array}$ \\
\hline 33 & $\begin{array}{l}\text { Copula. } \\
\text { Markov }\end{array}$ & 2019 & $\begin{array}{l}\text { Copula.Markov (copula-based estimation and statistical process control } \\
\text { for serially correlated time series) paketi, zaman serisi verilerine dayalı } \\
\text { Copula yöntemi ile ilgili kontrol grafiklerinin oluşturulması ve söz } \\
\text { konusu kontrol grafikleri ile ilgili tahminleri hesaplamak amacıyla } \\
\text { oluşturulan fonksiyonları kapsayan bir R paketidir. }\end{array}$ \\
\hline 34 & spc4sts & 2019 & $\begin{array}{l}\text { spc4sts (statistical process control for stochastic textured surfaces) paketi, } \\
\text { sağlık alanında doku yüzeyleri ile ilgili verilerin kalite kontrolünün } \\
\text { yapılması maksadıyla ihtiyaç duyulan kalite kontrol araçları için ge- } \\
\text { rekli fonksiyonları kapsayan bir R paketidir. }\end{array}$ \\
\hline
\end{tabular}




\begin{tabular}{|c|c|c|l|}
\hline 35 & strvalidator & 2019 & $\begin{array}{l}\text { strvalidator (process control and internal validation of forensic STR kits) } \\
\text { paketi, adli alan ile ilgili verilerin kalite kontrolünün yapılması ama- } \\
\text { cyla oluşturulmuş bir R paketidir. }\end{array}$ \\
\hline
\end{tabular}

Kaynak:"https://cran.r-project.org/web/packages/available_packages_by_name.h"

Tablo-1'de yer alan kalite kontrol grafikleri ile ilgili $R$ paketlerinin içerikleri incelendiğinde ilk üç paketin kalite kontrol grafiklerinin dizayn edilmesi ile ilgili olarak temel paketler olduğu ve diğer paketlerin ise kalite kontrol grafikleri ile ilgili daha spesifik ve ayrıntılı konular için oluşturulmuş paketlerin olduğu görülmektedir. Dolayısıyla R programının kalite kontrol grafikleri ile ilgili çok fazla imkân sunduğu şeklinde bir sonuca ulaşabiliriz. Ayrıca kalite kontrol grafikleri ile ilgili oluşturulmuş $\mathrm{R}$ paketlerinin oluşturulma tarihine göre gelişim grafiği Grafik-1'de yer almaktadır.

\section{Grafik-1. Yıllara Göre R Programında Oluşturulmuş Kontrol Grafikleri Paketleri}

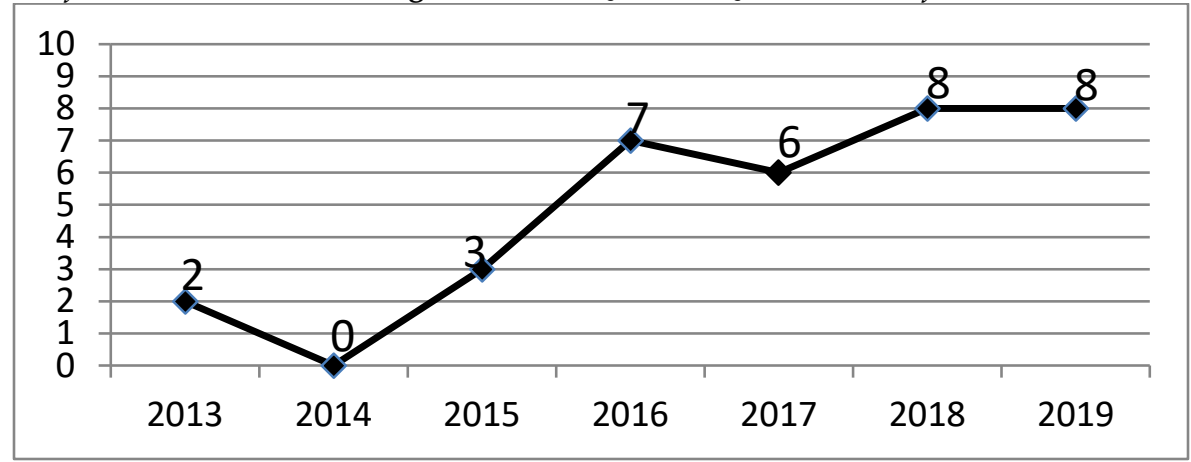

Grafik-1 incelendiğinde, kalite kontrol grafikleri ile ilgili olarak oluşturulan paketlerin yıllara sair olarak arttığı görülmektedir. Dolayısıyla $R$ programlama dili, kalite kontrol grafiklerinin dizayn edilmesinde oldukça uygun bir hesaplama aracı olduğu sonucuna ulaşabiliriz.

$\mathrm{R}$ programlama dilinin yaygın olarak kullanılan çeşitli $\mathrm{R}$ kullanıcı ara yüzleri vardır. $B u$ ara yüzler standart $R$ ara yüzü, $R$ Studio ara yüzü ve $R$ Commander ara yüzüdür. Konrath, Walter, Henning, Alves ve Samohyl (2013) tarafından yapılan çalışma kapsamında kalite kontrol grafiklerinin dizayn edilmesinde söz konusu arayüzlerden en uygununun R Studio arayüzünün olduğunu tespit etmiştir. 


\section{Yöntem}

Li ve Çavuşgil (1995)'e göre bir alanda veya bir konuda var olan bilgileri toplamak ve toplanan bu bilgileri düzenleyerek bir sonuç çıkarmak için literatürde üç temel yaklaşım bulunmaktadır. Bu yaklaşımlar delphi metodu, içerik analizi ve meta analizi yöntemleridir. Yapılan çalışmada bu yöntemlerden belirli kurallara dayalı kodlamalarla bir metnin bazı sözcüklerinin daha küçük içerik kategorileri ile özetlendiği sistematik, yinelenebilir bir teknik olan içerik analizi yöntemi kullanılmıştır (Büyüköztürk ve diğerleri, 2010:269). Cohen, Manion ve Morrison (2007)'a göre içerik analizi, eldeki yazılı yayınların içerdikleri bilgilerin temel içeriklerinin ve içerdikleri mesajların özetlenmesi ve derinlemesine analiz edilme işlemi olarak tanımlanmaktadır. İçerik analizinin sonucunda elde edilen verilerin değerlendirilmesi ve yorumlanmasında genellikle betimsel istatistik yöntemlerinden frekans ve yüzde kullanılır. İçerik analizi değişkenler arasındaki veya olgular arasındaki ilişkileri belirlemeye yönelik tasarlandığ 1 durumlarda çapraz tablolar ve sürekli olmayan verilerde ilişki derecesini ortaya koyan ki-kare analizlerinden sıklıkla yararlanılır (Orçanlı, Oktay ve Birgören, 2015).

Bu kapsamda belirlenen çalışmanın amacını gerçekleştirmek maksadıyla çalışmada araştırılan kitap ve makaleler Google akademik ve Web of Science veri tabanlarında arama motorları ile araştırılmıştır. Araştırma esnasında kullanılan çalışmalar, arama motorlarında aşağıda yer alan Türkçe ve İngilizce anahtar kelimeler tek tek ve çeşitli kombinasyonlar oluşturularak tespit edilmiştir. Araştırmada kullanılan anahtar kelimeler;

- "R", "R paketi", "R programi", "kalite", "kontrol grafikleri",

- "R", "R package", "R programming", "quality", "control charts" kelimeleridir. Bu kapsamda 4 adet kitap, 73 adet makale ve 23 adet Web sayfası bulunmuştur. Ancak çalışma ile ilgili olarak bulunan elektronik dokümanlardan yapılan inceleme neticesinde, 4 adet kitap ve 36 adet makale değerlendirmeye alınmıştır.

Çalışmalar içerik analizine uygun olarak Tablo-2'de yer alan sınıflandırma ölçeğine göre incelenmiştir. 
Kenan Orçanlı

Tablo-2. İçerik Analizi Kapsamında Oluşturulmuş Araştırma Ölçeği

\begin{tabular}{|c|c|c|c|}
\hline \multirow{2}{*}{$\mathrm{A}$} & \multirow{2}{*}{ Çalışmanın niteliği } & 1 & Teorik çalışmalar \\
\hline & & 2 & Uygulamalı çalışmalar \\
\hline \multirow{2}{*}{$\mathrm{B}$} & \multirow{2}{*}{ Verilerin Türü } & 1 & Yapay veriler \\
\hline & & 2 & Üretim sürecinden alınan gerçek veriler \\
\hline \multirow{2}{*}{$\mathrm{C}$} & \multirow{2}{*}{ Performans ölçütü } & 1 & $A R L$ \\
\hline & & 2 & Diğer \\
\hline \multirow{2}{*}{$\mathrm{D}$} & \multirow{2}{*}{$\begin{array}{l}\text { Değişken sayısına göre kontrol gra- } \\
\text { fiği }\end{array}$} & 1 & Tek değişkenli kontrol grafiği \\
\hline & & 2 & Çok değişkenli kontrol grafiği \\
\hline \multirow{6}{*}{$\mathrm{E}$} & \multirow{6}{*}{ Çalışmada kullanılan R paketi } & 1 & $q c c$ paketi \\
\hline & & 2 & MQSC paketi \\
\hline & & 3 & IQCC paketi \\
\hline & & 4 & edcc paketi \\
\hline & & 5 & spcadjust paketi \\
\hline & & 6 & Diğer paketler \\
\hline \multirow{7}{*}{$\mathrm{F}$} & \multirow{7}{*}{ Kontrol grafiğinin tipi } & 1 & $X-R, X-S, I-M R$ kontrol grafikleri \\
\hline & & 2 & EWMA, CUSUM kontrol grafikleri \\
\hline & & 3 & Diğer tek değişkenli kontrol grafikleri \\
\hline & & 4 & $n, n p, u, c$ ve diğer özellikli kontrol grafikleri \\
\hline & & 5 & $\begin{array}{l}\text { Hotelling } T^{2}, M E W M A, M C U S U M \text { kontrol grafik- } \\
\text { leri }\end{array}$ \\
\hline & & 6 & Bulanık kontrol grafikleri \\
\hline & & 7 & Diğer özel grafikler \\
\hline \multirow{6}{*}{ G } & \multirow{6}{*}{ Verilerin dağılımı } & 1 & Normal dağılım \\
\hline & & 2 & Gaussian dağılım \\
\hline & & 3 & Poisson dağılım \\
\hline & & 4 & Birnbaum-Saunders dağılım \\
\hline & & 5 & Conway-Maxwell-Poisson dağılım \\
\hline & & 6 & Dağılımı bilinmeyen dağılımlar \\
\hline
\end{tabular}




\begin{tabular}{|l|l|l|l|}
\hline \multirow{2}{*}{$\mathrm{H}$} & Sürecin parametrelerinin durumu & 1 & Faz I \\
\cline { 3 - 4 } & 2 & Faz II \\
\hline
\end{tabular}

\section{Uygulama}

Yapılan inceleme sonucunda kalite kontrol grafiklerinde $\mathrm{R}$ programının kullanımı ile ilgili olarak yerli ve yabancı literatürdeki kitapların yer aldığ 1 liste Tablo-3'tedir.

Tablo-3. R Programını Kalite Kontrol Grafiklerinde Kullanımı İle İlgili Kitaplar

\begin{tabular}{|c|l|c|l|}
\hline S.No & \multicolumn{1}{|c|}{ Yazarlar } & Y1li & \multicolumn{1}{c|}{ Kitaplar } \\
\hline 1 & Cano, E.L. & 2011 & $\begin{array}{l}\text { An Introduction to R for Quality Control } \\
\text { Universidad Rey Juan Carlos Publication. }\end{array}$ \\
\hline 2 & Santos-Fernández, E. & 2012 & $\begin{array}{l}\text { Multivariate Statistical Quality Control Using R } \\
\text { Springer New York Heidelberg Dordrecht Lon- } \\
\text { don. }\end{array}$ \\
\hline 3 & Qiu, P. & 2014 & $\begin{array}{l}\text { Introduction to Statistical Process Control } \\
\text { Boca Raton, FL: Chapman \& Hall/CRC. }\end{array}$ \\
\hline 4 & $\begin{array}{l}\text { Cano, E.L., Moguerza Ma- } \\
\text { riano J.M. ve Corcoba, }\end{array}$ & 2015 & $\begin{array}{l}\text { Quality Control with R An ISO Standards Appro- } \\
\text { ach Springer Cham Heidelberg New York } \\
\text { Dordrecht London. }\end{array}$ \\
\hline
\end{tabular}

Tablo-3'de yer alan kitaplar hakkında özet bilgi müteakip paragraflarda verilmiştir.

Cano (2011) tarafından hazırlanan yüksek lisans tezinde, kalite kontrolü için R programlama dilinin kullanımı ve MINITAB ile karşılaştırması sonucunda elde edilen teorik bilgileri vermiştir. Ayrıca neden-etki diyagramı ve altı sigma yaklaşımında R programlama dilinin kullanılması ve kalite karakteristiklerinin ölçülmesi ile ilgili teorik bilgiler vermiş ve bu kapsamda yazılan R kodlarını tanıtmıştır.

Santos-Fernández (2012) tarafından hazırlanan kitapta, R programının tanıtımı ve kalite kontrolünde kullanımı, çok değişkenli kontrol grafikleri ile ilgili temel bilgiler ve varsayımları, 5 adet çok değişkenli kontrol grafiğinin (Hotelling $T^{2}$ kontrol grafiği, MEWMA kontrol grafiği, MCUSUM kontrol grafiği, genelleştirilmiş varyans kontrol grafiği ve temel bileşenler analizine dayalı olarak oluşturulan kontrol grafiği) 
dizayn edilmesi, çok değişkenli süreçlerde yeterlilik analizi ile bu konuların $\mathrm{R}$ programı ile nasıl yapılacağı ve uygulama örnekleri anlatılmıştır.

Qiu (2014) tarafından hazırlanan kitapta, kontrol grafikleri ile ilgili temel bilgiler, tek ve çok değişkenli kontrol grafiklerinin oluşturulması, tek ve çok değişkenli süreç yeterlilik analizi, profil izleme, tek ve çok değişkenli parametrik olmayan kontrol grafikleri ve bu konularda $R$ paketleri ve kodları anlatılmıştır. Ancak kitapta kontrol grafiklerinde R programlama dilinin uygulanması ile ilgili verilen bilgilerin sınırlı olduğu görülmüştür.

Cano, Moguerza Mariano ve Corcoba (2015) tarafından hazırlanan kitapta, R ortamında kalite kontrolün nasıl yapıldığı, süreç yeterlilik analizi, süreç kontrolünde kullanılan kalitenin yedi muhteşem aracı ve bu araçların ISO standartlarında kullanımı, kalite kontrolde kullanılan dağılımlar ve örnekleme yöntemleri, lineer olmayan profillerde kalite kontrol uygulamaları, özellikler ve değişkenler için dizayn edilen kalite kontrol grafikleri, kalite kontrolünde kullanılan bazı $\mathrm{R}$ paketleri ile belirtilen konuların $\mathrm{R}$ ortamında nasıl kullanılması gerektiği anlatılmaya çalışılmıştır.

R programının kalite kontrol grafiklerinde kullanımı ile ilgili olarak yerli ve yabancı literatürde hazırlanmış olan 36 adet makale, Tablo-2'de yer alan içerik analizi araştırma ölçeğine uygun olarak gruplanmış şekilde Tablo-4'te yer verilmiştir. 
Tablo-4. R Programı ve Kalite Kontrol Grafikleri İle İlgili Makaleler Listesi

\begin{tabular}{|c|c|c|c|c|c|c|c|c|c|c|c|c|c|c|c|c|c|c|c|c|c|c|c|c|c|c|c|c|c|c|c|}
\hline \multirow{2}{*}{$\begin{array}{l}\text { S. } \\
\text { No }\end{array}$} & \multirow{2}{*}{ Yazararlar } & \multirow{2}{*}{ Yil } & \multicolumn{2}{|c|}{ A } & \multicolumn{2}{|c|}{ B } & \multicolumn{2}{|c|}{ C } & \multicolumn{2}{|c|}{ D } & \multicolumn{6}{|c|}{ E } & \multicolumn{7}{|c|}{ F } & \multicolumn{6}{|c|}{ G } & \multicolumn{2}{|c|}{ H } \\
\hline & & & 1 & 2 & 1 & 2 & 1 & 2 & 1 & 2 & 1 & 2 & 3 & 4 & 5 & 6 & 1 & 2 & 3 & 4 & 5 & 6 & 7 & 1 & 2 & 3 & 4 & 5 & 6 & 1 & 2 \\
\hline 1 & $\begin{array}{l}\text { Morton, A., } \\
\text { Gatton, M., } \\
\text { Tong, E.B.A, } \\
\text { Clements, A. }\end{array}$ & 2007 & * & & & $*$ & & & & $*$ & & & & & & $*$ & $*$ & $*$ & & & & & & $*$ & & & & & & & $*$ \\
\hline 2 & Hö̆le M. & 2007 & * & & & & & & & & & & & & & * & & & & & & & & $*$ & & & & & & & \\
\hline 3 & $\begin{array}{l}\text { Lio, Y.L. ve } \\
\text { Park, C. }\end{array}$ & 2008 & * & & $*$ & & $*$ & & & $*$ & & & & & & $*$ & & & & & & & * & & & & * & & & & $*$ \\
\hline 5 & $\begin{array}{l}\text { Alfaro, E., Al- } \\
\text { faro, J.L. } \\
\text { Gámez, M. ve } \\
\text { Garcia, N. }\end{array}$ & 2009 & * & & $*$ & & & & & $*$ & & & & & & $*$ & & & & & $*$ & & & $*$ & & & & & & & * \\
\hline 6 & $\begin{array}{l}\text { Alfaro, J.L. ve } \\
\text { Ortega, J.F. }\end{array}$ & 2009 & * & & $*$ & & & & & * & & & & & & $*$ & & & & & $*$ & & & $*$ & & & & & & & $*$ \\
\hline 7 & $\begin{array}{l}\text { Capizzi, G. ve } \\
\text { Masarotto, G. }\end{array}$ & 2010 & * & & $*$ & & $*$ & & $*$ & & & & & & & * & $*$ & $*$ & & & & & * & $*$ & & & & & & & $*$ \\
\hline 9 & $\begin{array}{l}\text { Lio, Y.L. ve } \\
\text { Park, C. }\end{array}$ & 2010 & $*$ & & $*$ & & $*$ & & * & & & & & & & $*$ & $*$ & & & & & & & & $*$ & & & & & & $*$ \\
\hline
\end{tabular}




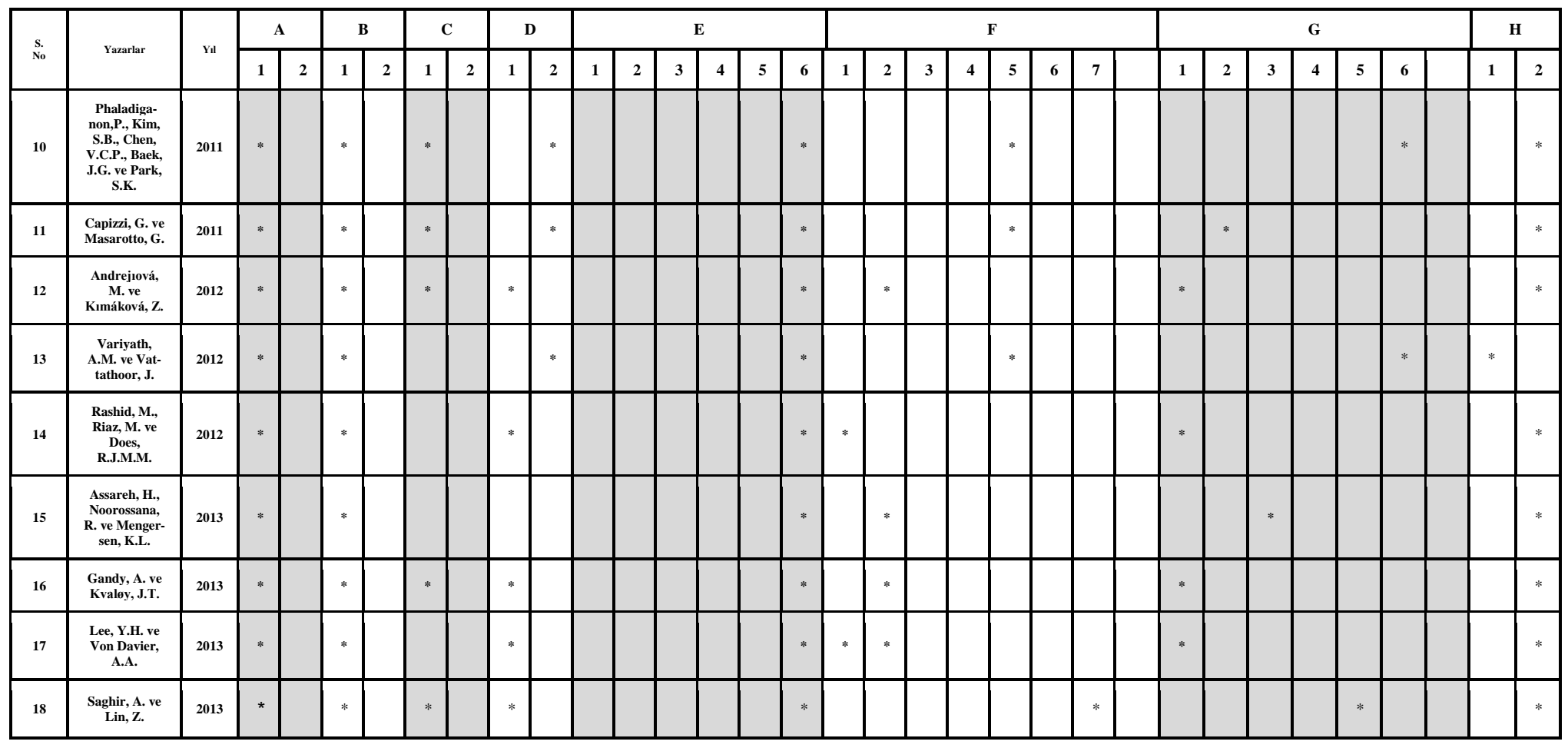




\begin{tabular}{|c|c|c|c|c|c|c|c|c|c|c|c|c|c|c|c|c|c|c|c|c|c|c|c|c|c|c|c|c|c|c|c|}
\hline \multirow{2}{*}{$\begin{array}{l}\text { S. } \\
\text { No }\end{array}$} & \multirow{2}{*}{ Yazarlar } & \multirow{2}{*}{ Yul } & \multicolumn{2}{|c|}{$\mathbf{A}$} & \multicolumn{2}{|c|}{ B } & \multicolumn{2}{|c|}{ C } & \multicolumn{2}{|c|}{ D } & \multicolumn{6}{|c|}{ E } & \multicolumn{7}{|c|}{$\mathbf{F}$} & \multicolumn{6}{|c|}{ G } & \multicolumn{2}{|c|}{ H } \\
\hline & & & 1 & 2 & 1 & 2 & 1 & 2 & 1 & 2 & 1 & 2 & 3 & 4 & 5 & 6 & 1 & 2 & 3 & 4 & 5 & 6 & 7 & 1 & 2 & 3 & 4 & 5 & 6 & 1 & 2 \\
\hline 19 & $\begin{array}{l}\text { Konrath, } \\
\text { A.C., Walter, } \\
\text { O.M.F.C., } \\
\text { Henning, E., } \\
\text { Alves, C.C. ve } \\
\text { Samohyl, } \\
\text { R.W. }\end{array}$ & 2013 & $*$ & & $*$ & & & & $*$ & & & & & & & * & $*$ & $*$ & & & & & & * & & & & & & & $*$ \\
\hline 20 & $\begin{array}{l}\text { Henning, E., } \\
\text { Maia, M.T., } \\
\text { Walter, } \\
\text { O.M.F.C., } \\
\text { Konrath, A.C. } \\
\text { ve Alves, C.C. }\end{array}$ & 2014 & $*$ & & $*$ & & & & * & $*$ & * & & & & & & $*$ & & & & $*$ & & & $*$ & & & & & & & $*$ \\
\hline 21 & $\begin{array}{l}\text { Bell, R.C., } \\
\text { Jones.Farmer, } \\
\text { L.A. ve Billor, } \\
\text { N. }\end{array}$ & 2014 & $*$ & & $*$ & & & & & $*$ & & & & & & $*$ & & & & & $*$ & & & & & & & & * & $*$ & \\
\hline 22 & $\begin{array}{l}\text { Chananet,C. } \\
\text { Sukparungsee, } \\
\text { S. ve Areepon, } \\
\text { Y. }\end{array}$ & 2014 & * & & $*$ & & * & & & * & & & & & & * & & & & & & & * & $*$ & & & & & & & $*$ \\
\hline 25 & Farkas, K. & 2015 & * & * & & * & & & ${ }^{*}$ & & * & & & & & & & * & & & & & & ${ }^{*}$ & & & & & & & $*$ \\
\hline 26 & Knoth,S. & 2015 & $*$ & & $*$ & & $*$ & & $*$ & & & & & & & $*$ & & $*$ & & & & & & $*$ & & & & & & & $*$ \\
\hline
\end{tabular}




\begin{tabular}{|c|c|c|c|c|c|c|c|c|c|c|c|c|c|c|c|c|c|c|c|c|c|c|c|c|c|c|c|c|c|c|c|}
\hline \multirow{2}{*}{$\begin{array}{l}\mathrm{S} . \\
\mathrm{No}\end{array}$} & \multirow{2}{*}{ Yaazarlar } & \multirow{2}{*}{$\mathrm{yu}$} & \multicolumn{2}{|c|}{$\mathbf{A}$} & \multicolumn{2}{|c|}{ B } & \multicolumn{2}{|c|}{ C } & \multicolumn{2}{|c|}{ D } & \multicolumn{6}{|c|}{$\bar{E}$} & \multicolumn{7}{|c|}{$F$} & \multicolumn{6}{|c|}{ G } & \multicolumn{2}{|c|}{ H } \\
\hline & & & 1 & 2 & 1 & 2 & 1 & 2 & 1 & 2 & 1 & 2 & 3 & 4 & 5 & 6 & 1 & 2 & 3 & 4 & 5 & 6 & 7 & 1 & 2 & 3 & 4 & 5 & 6 & 1 & 2 \\
\hline 27 & Sündüs, D.A. & 2015 & $*$ & * & & * & * & & $*$ & & & & & $*$ & & & $*$ & $*$ & & & & & & * & & & & & & & $*$ \\
\hline 30 & $\begin{array}{l}\text { V. Giner- } \\
\text { Bosch, C. Ca- } \\
\text { banos ve A. } \\
\text { Debón-Aucejo }\end{array}$ & 2016 & $*$ & * & & * & & & & * & * & & & & & * & & * & & & & & & * & & & & & & & * \\
\hline 32 & $\begin{array}{l}\text { Chiang, J.Y., } \\
\text { Liob, Y.L. ve } \\
\text { Tsaic, T.R. }\end{array}$ & 2017 & * & & $*$ & & & & & * & & & & & & * & & & & & $*$ & & & $*$ & & & & & & & * \\
\hline 33 & Orçanlı, $\mathbf{K}$. & 2017 & $*$ & & $*$ & & & & & * & & & & & & * & * & * & & & * & & & * & & & & & & & * \\
\hline 34 & $\begin{array}{l}\text { McCarthy, } \\
\text { Camphell, } \\
\text { Lun ve Wills }\end{array}$ & 2017 & $*$ & & * & & & & & & & & & & & * & & & & & & & & * & & & & & & & * \\
\hline 36 & Veljkovic, K. & 2019 & $*$ & & $*$ & & & & * & & & & & & & $*$ & * & & & & & & & & & & & & $*$ & & * \\
\hline
\end{tabular}


Tablo-4'te yer alan makaleler hakkında özet bilgiler müteakip paragraflarda verilmiştir.

Morton, Gatton, Tong ve Clements (2007) tarafından yapılan çalışmada, sağlık sektöründe çok değişkenli antibiyotik dirençli organizmaları ile ilgili verilerin kontrol grafikleri ile izlenebileceği, ancak bu verilerin arasında korelasyon ve otokorelasyonun olması durumunda gözlemlerin söz konusu geleneksel kontrol grafikleri ile izlenemeyeceği belirtilmiş ve bu kapsamda GAMM (generalized additive mixed model) kontrol grafikleri önerilmiştir. Çalışma gerçek veriler ile yapılmıştır. Önerilen kontrol gtafiğinde kullanılan verilerin korelasyon durumunun incelenmesinde R mgcv paketinde yeralan GAMM fonksiyonu kullanılmış ve kontrol grafiğinin oluşturulmasında ihtiyaç duyulan kodlar sorumlu yazar tarafından $\mathrm{R}$ ortamında yazılmıştır. Önerilen kontrol grafiği $X$ ve EWMA kontrol grafiğini temel almış ve yapılan çalışmada önerilen kontrol grafiklerinin çizimi yine R ortamında yapılmıştır.

Höhle (2007) tarafından yapılan çalışmada, sağlık alanında ani olarak çıkan bazı enfeksiyonları tespit etmek amacıyla $\mathrm{R}$ surveilence paketini önermiştir.

Lio ve Park (2008) tarafından yapılan çalışmada, Birnbaum-Saunders dağılımına uygun olarak dağılan kalite karakteristiklerindeki kaymayı tespit etmek amaciyla yeni bir bootstrap kontrol grafiği önerilmiştir. Bu kapsamda R ortamında Birnbaum-Saunders dağılımı için Leiva, Hernandez ve Riquelme (2006) tarafından önerilmiş bir paket kullanılmış, Birnbaum-Saunders dağılımına uygun olarak dağılan kalite karakteristiklerinin izlenmesi için önerilen çok değişkenli kontrol grafiği $\mathrm{R}$ ortamında dizayn edilmiş ve söz konusu kontrol grafiğinin performansı için ihtiyaç duyulan $A R L$ değerleri yine R ortamında hesaplanmıştır.

Vargas, Alfaro ve Mondéjar (2009) tarafından yapılan çalışmada, otokorelasyonlu verilere sahip kalite karakteristiği için çok değişkenli State-Space kontrol grafiği önerilmiştir. Söz konusu önerilen kontrol grafiğinde çok değişkenli verileri elde etmek için Alan Genz'in R motnorm paketinde bulunan rmonorm fonksiyonu ve oluşturulan VAR modelin tahmincileri elde etmek amaciyla Paul Gilbert'in $\mathrm{R}$ dse paketinde bulunan estVARXls fonksiyonu kullanılmıştır. Çalışmada yapay veriler ve performans ölçümünde $A R L$ değerleri kullanılmıştır. Alan Genz'in ve Paul 
Gilbert'in R paketleri ile ilgili detaylı bilgiler google arama motorunda "R packages by name" ile aranarak bulunabilir.

Alfaro, Alfaro, Gámez ve García (2009) tarafindan yapılan çalışmada, çok değişkenli kontrol grafiklerinde meydana gelen kaymanın nedenini belirlemenin veya hangi değişken veya değişken gruplarından kaynaklandığının tespit edilmesinin güç olduğunu belirtmekte olup söz konusu problemin çözümü için sinıflandırma işlemlerinde kullanılan karar ağaçları yöntemi ile çözülebileceğini öne sürmektedir. Sınıflandırma işlemlerinde $S A M M E$ algoritması (the stagewise additive modelling using a multi-class exponential loss function algorithm) ve Hotelling $T^{2}$ kontrol grafiğ $\mathrm{i}$ kullanılmıştır. R ortamında uygulamasının yapılması önerilen işlemde Alfaro, Gamez ve Garcia (2006) tarafından oluşturulan Adabag paketinde yeralan AdaBoost fonksiyonu kullanılmıştır. Çalışmada çeşitli düzeylerde kayma ile ilgili oluşturulan senaryolarda yapay veriler kullanılmıştır.

Alfaro ve Ortega (2009) tarafından yapılan çalışmada, Faz I aşamasında sürecin parametrelerin belli olmamasından dolayı aykırı veri analizinin yapıldığı ve bu analiz sonunda elde edilen parametre değerlerinin Faz II aşamasında kontrol grafiklerinin dizayn edilmesinde kulllanılması gerektiği belirtilmekle beraber eğer aykırı değerler bulunduğu anda kontrol grafiğinin dizayn edilmesi gerekiyorsa etkilerin maskelenmesi (masking effect) yöntemine bağlı olarak kontrol grafilerinin dizayn edilebileceği belirtilmektedir. Bu kapsamda yapılan çalışmada, Faz II'de kullanılabilecek parametrelerin minimum volume ellipsoid, minimum kovaryans determinantı ve ağırlıklandırılmış minimum kovaryans determinantı tahmincileri Monte Carlo simülasyonu ile hesaplanarak (yapay veriler) performans karşılaştırılması yapılmıştır. Çalışmada kontrol grafiklerinin tahmincileri, geleneksel ve sağlam ortalama değerleri ve diğer gerekli hesaplamalar R ortaminda MASS paketinde yeralan cov.mve ve cov.mcd fonksiyonları, $\operatorname{rrcov}$ paketinde yeralan covMcd fonksiyonu ile Hotelling $T^{2}$ istatistiği kullanılmıştır.

Capizzi ve Masarotto (2010) tarafından yapılan çalışmada, kontrol grafiklerinde aynı anda hem küçük hem de büyük kaymaları tespit etmek amacıyla Shewhart ve EWMA control grafiklerinin aynı anda özellikleri taşıyan CSEWMA isimli bir adet kalite kontrol grafiği önerilmiştir. Çalışmada, kontrol grafiğinin oluşturulmasında $\mathrm{R}$ paketlerinden $s p c$ paketi, kontrol grafiğinin performansının ölçülmesinde Monte Carlo 
simülasyonu ile $A R L$ değerleri ve verilerin elde edilmesinde yapay veriler kullanılmıştır.

Bush, Chongfuangprinya, Chen, Sukchotrat ve Kim (2010) tarafından yapılan çalışmada, parametrik olmayan k-link sıralı algoritmasına dayalı $k L i n k$ kontrol grafiği önerilmiştir. Söz konusu önerilen kontrol grafiği geleneksel Hotelling $T^{2}$ ve parametrik olmayan ranking depth kontrol grafiği ile karşılaştırılmıştır. Ayrıca ek olarak önerilen kLink kontrol grafiğinin ağırlıklandırılmış EWMA versiyonununda nasıl oluşturulacağı anlatılmıştır. Çalışmada kontrol grafiklerinin karşılaştııılmasında $A R L$ değerleri ile parametrik olmayan ranking depth kontrol grafiğinin geliştirilmesinde $\mathrm{R}$ depth paketinde depth fonksiyonu kullanılmıştır. Ayrıca verilerde Gamma dağılımından yararlanılmıştır.

Lio ve Park (2010) tarafından yapılan çalışmada, Shewhart kontrol grafiklerinin normal dağılan kalite karakteristikleri için uygun olduğu, ancak normal dağılmayan veya dağılımı bilinmeyen kalite karakteristikleri için uygun olmadığı belirtilmektedir. Bu kapsamda Lio ve Park (2010), ters Gaussian dağılımına sahip gözlemleri izlemek amacıyla parametrik bootstrap kontrol grafiğini önermiştir. Ters Gaussian dağılımına sahip gözlemlerin üretilmesinde Wheeler (2008) tarafından oluşturulmuş $\mathrm{R}$ paketi ile önerilen kontrol grafiğinin performansının hesaplanmasında Monte Carlo simülasyonu yardımı ile $A R L$ değerlerinin elde edilmesinde $\mathrm{R}$ programında yazılan kodlar kullanılmıştır.

Phaladiganon, Kim, Chen, Baek ve Park (2011) tarafindan yapılan bir teknik raporda, normal dağılmayan veya dağılımı bilinmeyen verileri izlemek amacıyla çok değişkenli bootstrap $T^{2}$ kontrol grafiği önermiş ve geleneksel Hotelling $T^{2}$ kontrol grafiği ile çekirdek yoğunluk tahmincili $T^{2}$ kontrol grafiği ile $A R L$ değerleri elde edilerek performans karşılaştırılması yapılmıştır. Çalışmada gerçek veriler ve çok değişkenli yamuk (skew)normal verileri üretmek amacıyla $\mathrm{R}$ ortaminda yazılan kodlar kullanılmıştır.

Capizzi ve Masarotto (2011) tarafından yapılan çalışmada, çok değişkenli süreçlerde Gaussian dağılımına uygun kalite karakteristiklerinin Faz II aşamasında izlenmesi amacıyla MEWMA kontrol grafiği ile en düşük aç1l regresyon algoritmasını (the least angle regression algorithm) müşterek kullanan yeni bir kontrol grafiği önerilmiştir. Söz konusu kontrol grafiğinde ortalamada değişim noktaları ile regresyon 
katsayılarındaki kaymaları kapsayan çeşitli senaryoların belirlenmesine yönelik R paketinden (larewma_1.0.tar.gz) yararlanılmıştır. Ayrıca önerilen kontrol grafiğinin performansı, $\mathrm{R}$ paketinde yer alan semiconductor üretim sürecindeki DRIE (deep-reactive ion-etching) prosesinden alınan örneklerden yararlanılarak $A R L$ değerlerine göre değerlendirilmiştir.

Andrejıvá ve Kımáková (2012) tarafından yapılan çalışmada, kontrol grafiklerinin kullanılması için sürecin kontrol altında olması gerektiğini belirtmiş, ancak kontrol altında olmadığında kullanılması durumunda ise kontrol grafiğinin performansının düştüğü ve yüksek oranda kontrol dışının oluştuğunu belirtmektedir. Bu kapsamda bu eksikliği gidermek amacıyla bootstrapping örneklemeye dayalı bir yöntem önermiştir. Önerilen yöntem çeşitli kontrol grafiklerinde ve regresyona dayalı olarak oluşturulan kontrol grafiklerinde de kullanılabileceği ifade edilmektedir. Çalışmalar R spcadjust paketine dayalı olarak yapılmıştır. Yapılan tüm çalışma boyunca bütün işlemler CUSUM kontrol grafiğinde yapılmış, çeşitli senaryolar kapsamında performans ölçümünde $A R L$ değerleri, simülasyonda ise $\mathrm{R}$ ortamında üretilen yapay veriler kullanılmıştır.

Variyath ve Vattathoor (2013) tarafından yapılan çalışmada, Hotelling $T^{2}$ kontrol grafiğinin Faz I aşamasının oluşturulması aşamasında ortalama ve varyansın elde edilmesinde tekrar ağırlıklandırılmış minimum kovaryans determinantı (the reweighted minimum covariance determinant $(R M C D)$ ) ve tekrar ağırlıklandırılmış minimum alan elipsoidi (the reweighted minimum volume ellipsoid (RMVE))'ne dayalı tahmincileri elde etmek amacıyla dayanıklı kontrol grafiği önerilmiştir. Çalışmada Monte Carlo simülasyonu ve yapay veriler kullanılmıştır. Söz konusu işlemlerde $\mathrm{R}$ rrcov paketi ve bu pakette yeralan CovMcd() fonksiyonu kullanılmıştır.

Rashid, Riaz ve Does (2012) tarafından yapılan çalışmada, Shewhart kontrol grafiğinde oluşan kontrol dışı sinyallerin yorumlanması le ilgili $\mathrm{R}$ ortamında kodlar yazarak STATA, SAS, MAPLE ve diğer çalışma ortamlarına ek olacak şekilde uygulamalar yaratmıştır. Söz konusu geliştirilen kurallar kapsamında power isimli bir $\mathrm{R}$ paketi oluşturulmuş ve $\mathrm{R}$ kütüphanesine girilmiştir. Uygulama örnekleri yapay veriler ile Xbar, $R$, $S$ ve $S^{2}$ kontrol grafiklerinde çeşitli senaryolara göre yapılmıştır.

Assareh, Noorossana ve Mengersen (2013) tarafindan yapilan çalışmada, süreci etkileyen özel bir neden olduğunda parametrelerde, kontrol sinırlarında ve kalite karakteristiklerinde meydana gelen 
kaymaların tespit edilmesinde c-, Poisson EWMA ve Poisson CUSUM kontrol grafiklerinde çeşitli senaryolar kapsamında bazı araştırmalar yapılmıştır. Yapılan çalışmada tüm simülasyon işlemlerinde Monte Carlo simülasyonu, yapay veriler ve Plummer, Best, Cowles ve Vines (2010) tarafından oluşturulan $\mathrm{R}$ coda paketi kullanılmıştır.

Gandy ve Kvaløy (2013) tarafından yapılan çalışmada, kontrol grafiklerinin oluşturulması esnasında gerekli olan parametrelerin sürecin kontrol altında iken elde edilebildiği ve bu değerlerin tam hesap edilememesi durumunda kontrol grafiğinin performansının ölçülmesi için hesaplanması gereken $A R L$ değerlerinde sapmalar oluşabileceği ve bu kapsamda söz konusu problemlerin çözümü için bir yöntem önerilmiştir. Önerilen yöntem regresyon tabanlı bir yöntemdir. Çalışmada yapay veriler, CUSUM kontrol grafiği ve Markov Zinciri yaklaşımı kullanılmıştır.

Lee ve Von Davier (2013) tarafından yapılan çalışmada, eğitim alanında değerlendirme standartlarını belirlemek ve bu standartlardan sapmaları tespit etmek amacıyla kontrol grafiklerinin kullanılabileceği belirtilmektedir. Bu kapsamda yeni bir yaklaşım önerilmiş ve önerilen yaklaşım gerçek şartlarda denenmiştir. Çalışmada kontrol grafikleri olarak $X$ ve CUSUM kontrol grafikleri, farklı HMM'leri uydurmak amaciyla $\mathrm{R}$ ortamında depmixS4 paketi kullanılmıştır.

Saghir ve Lin (2013) tarafından yapılmış çalışmada, Conway-MaxwellPoisson dağılımına uyan özellikli kalite karakteristiklerinin izlenmesi amacıyla GEWMA kontrol grafiği önerilmiştir. Çalışmada $\mathrm{R}$ compoission paketi kullanılmış, bu paket ile parametre değerleri hesaplanmış ve yapay veriler üretilmiş, Monte Carlo simülasyonu ile $A R L$ değerleri hesaplanarak önerilen kontrol grafiğinin performansı ölçülmüştür.

Konrath, Walter, Henning, Alves ve Samohyl (2013) tarafından yapılan çalışmada, kontrol grafiklerinin $\mathrm{R}$ ortamında oluşturulmasında çeşitli $\mathrm{R}$ arayüzlerinde ( $R$ Commander, RStudio ve RExcel) nasıl dizayn edilmesi gerektiği ile ilgili bir uygulama yapılmıştır. Çalışmada CUSUM ve EWMA kotrol grafiklerinin dizayn edilmesi ele alınmış ve uygulama örnekleri yapay veriler ile yapılmıştır. Çalışmanın sonunda kalite kontrol grafiklerinin dizayn edilmesinde en kullanıcı dostu ve en zengin içeriğe sahip arayüzün RStudio olduğu ortaya konulmuştur.

Henning, Maia, Walter, Konrath ve Alves (2014) tarafindan yapilan çalışmada, bir fabrikada üretim sürecinde $X$-S kontrol grafiği ile Hotelling 
$T^{2}$ kontrol grafiği kullanılarak süreç kontrol uygulaması yapılmıştır. Kontrol grafiklerinin oluşturulmasında, verilerin normallik ve otokorelasyon ile ilgili varsayımlarının kontrol edilmesinde R ortamında Scrucca (2004) tarafından oluşturulan qcc paketi, Santos-Fernandes (2013) tarafından oluşturulan MSCQ paketi ve Mcneil ve Ulman (2011) tarafından oluşturulan QRMlib paketi kullanılmıştır.

Bell, Jones-Farmer ve Billor (2014) tarafından yapılan çalışmada, kontrol grafiklerinin başlangıç parametrelerinin bilinmediği anda uygulanan Faz I aşaması için normal dağılmayan kalite karakteristikleri için kullanılabilecek ve tahmin edilen parametreleri Faz II aşamasında da kullanılabilecek bir kontrol grafiği önerilmiştir. Çalışma Hotelling $T^{2}$ kontrol grafiğinde yapay veriler kullanılarak Monte Carlo simülasyonu yardımı ile denenmiştir. Çalışmada bazı işlemlerin yapılmasında $\mathrm{R}$ depth paketinden istifade edilmiştir.

Chananet, Sukparungsee ve Areepon (2014) tarafindan yapılan çalışmada, iki kategorili kalite karakteristiklerini izlemek amacıyla kurulan EWMA kontrol grafiğinin ARL değerlerinin Markov Zinciri yaklaşımı ile değerlendirmek için bir yöntem önerilmiştir. Çalışmada, Monte Carlo simülasyonu yaklaşımı, R VGAM paketi ve yapay veriler kullanılmıştır.

Radziwill (2015) tarafından internet sitesinde yapılan bir çalışmada, tek değişkenli kontrol grafikleri ve süreç yeterliliği ile ilgili olarak teorik bilgiler verilmiş ve konular ile ilgili verilen bilgilerin uygulamalarının $\mathrm{R}$ ortamında nasıl yapılacağı qcc paketi kullanılarak anlatılmıştır. Çalışmada uygulama örnekleri yapay veriler kullanılarak gösterilmiştir.

Veljkovic, Elfaghihe ve Jevremovic (2015) tarafından yapilan çalışmada, normal dağılmayan kalite karakteristikleri kullanılarak $X$ kontrol grafiğinin ekonomik istatistiksel dizaynı yapılmıştır. Normal dağılmayan veriler için student, standart Laplace ve lojistik dağımlarından faydalanılarak teorik dağılım normal dağılım, Pearson VII ve Johnson SU dağılımlarına uygun teorik veriler üretilerek ekonomik $X$ konrol grafiği dizayn edilmeye çalışılmıştır. Çalışmada beklenen kayıp fonksiyonun kıstlı minimizasyonu $\mathrm{R}$ ortamında bulunan GA (genetik algoritma) paketindeki ga fonksiyonu kullanılmıştır. Çalışmada yapay veriler kullanılmıştır. 
Farkas (2015) tarafından yapılan çalışmada, CUSUM kontrol grafiğinde tespit edilen kontrol dışı sinyalin tespiti ve teşhis için CUSUM anomali teşhisi yöntemini önermiştir. Araştırmacılar söz konusu çalışmalarında Scrucca (2004) tarafından oluşturulan R qcc paketini kullanmışlardır. Yapılan çalışmada gerçek veriler kullanılarak sonuçlar test edilmiştir.

Knoth (2015) tarafından yapılan çalışmada, EWMA kontrol grafiğinin $A R L$ değerlerini quantile değerleri yardımıyla hesaplanması için çeşitli denemeler yapılmıştır. Çalışmada, yapay veriler ve $\mathrm{R} s p c$ paketi kullanılmıştır.

Sündüs (2015) tarafından yapılan çalışmada, gerçek bir üretim sürecinde X-bar, EWMA ve CUSUM kontrol grafikleri ekonomik dizayninı yapmış ve söz konusu kontrol grafiklerinin performanslarını ise saat başı beklenen maliyet kriterine göre karşılaştırılmıştır. Çalışmada Zu ve Park (2013) tarafından oluşturulan $\mathrm{R}$ edcc paketi, gerçek veriler ve $A R L$ değerleri kullanılmıştır.

Vives-Mestres, Daunis-i-Estadella ve Martin-Fernandez (2015) tarafından yapılan çalışmada, compositional veriler için compositional $T^{2}$ kontrol grafiği önerilmiştir. Söz konusu grafiğin oluşturulmasında Van den Boogaart, Tolosana ve Bren (2014) tarafından oluşturulan R compositions paketi kullanılmıştır. Çalışma verileri gerçek üretim sürecinden alınarak kullanılmıştır.

Capizzi ve Masarotto (2016) tarafından kontrol grafiklerin limitlerinin skotastik süreçler kullanılarak oluşturulmasına ve geliştirilmesine yönelik bir çalışma yapılmıştır. Çalışmada, T²-MEWMA, AGLR ve çeşitli 4 adet parametrik olmayan EWMA kontrol grafiklerinin birleşiminden oluşturulmuş bir kontrol grafiğinden yararlanılmıştır. Kontrol grafiklerinin ile ilgili bazı hesaplamalarda Varadhan ve Gilbert (2009) tarafından önerilen $\mathrm{R} B B$ paketi ve bu paketten nleqslv fonksiyonu kullanılmıştır. Ayrıca kontrol grafiklerinin performansları, $\mathrm{R}$ ortaminda hesaplanan $A R L$ değerlerine göre çeşitli senaryolara göre karşılaştırılmıştır.

Giner-Bosch, Cabanos ve Debón-Aucejo (2016) tarafından yapılan çalışmada, EWMA ve CUSUM kontrol grafikleri, tahmin ve lineer olarak kurulan modeller ile ilgili yapilan hesaplamalarda R forecast paketi, zaman serisi veriler ile ilgili istatistiklerinin hesaplanmasında $R$ tseries paketi ve kalite kontrolü ile ilgili işlemlerde $\mathrm{R} q c c$ paketi ve ikincil gerçek veriler kullanılmıştır. 
Kuvattana, Busababodhin, Areepong ve Sukparungsee (2016) tarafından yapılan çalışmada, üssel dağılımdan gelen ve 4 adet farklı copula fonksiyonu ile birbirine bağlı kalite karakteristiklerini izlemek amacıyla çeşitli MEWMA kontrol grafikleri oluşturulmuş ve R ortamında yapay veriler yaratılarak Monte Carlo simülasyonu yardımıyla söz konu kontrol grafiklerinin $A R L$ değerlerine göre performansları karşılaştırılmıştır.

Chiang, Liob ve Tsaic (2017) tarafından yapılan çalışmada, Faz II aşamasında kullanılmak üzere otokorelasyonlu profil kalite karakteristiklerini izlemek maksadiyla MEWMA-SLP (MEWMA-simple linear profiles) kontrol grafiği ile bu tip süreçlerin yeterliliğinin bir ölçütü olarak iki adet süreç yeterlilik indeksi önerilmiştir. Yapılan çalışmada $R$ paketlerinden motnorm paketi ve bu pakette yeralan pmonorm fonksiyonu ile pracma paketi ve bu pakette yeralan triquad fonksiyonu kullanılmıştır.

Orçanlı (2017) tarafından yapılan çalışmada, süreç tabanlı temel gösterimlerine dayalı olarak oluşturulan Hotelling $T^{2}$ kontrol grafiğinde oluşan kontrol dışı örüntüleri yapay sinir ağları yöntemi ile tespit etmeye yönelik bir yöntem önermiştir. Yapılan çalışmada her sınıfı oluşturan kontrol dışı durumları temsil eden örüntüler $\mathrm{R}$ ortamında yazılan kodlar ile elde edilmiştir. Çalışmada, yapay ve gerçek veriler müşterek olarak kullanılmıştır.

McCarthy, Campbell, Lun ve Wills (2017) tarafından yapılan çalışmada, sağlık alanında kalite control çalışmları ile ilgili yapay veriler kullanılarak R scatter paketini geliştirmiştir. Yapay verilerin üretimesinde ise R mooutlier paketinden pcout fonksiyonu kullanılmıştır.

Marchant, Leiva, Cysneiros ve Liu (2018) tarafından yapılan çalışmada, Birnbaum-Saunders dağılımına uyan veriler için Hotelling $T^{2}$ istatistiğine uydurulan Faz I ve Faz II aşamalarını kapsayan yeni bir kontrol grafiği önerilmiştir. Çalışmada gerçek veriler kullanılarak söz konusu önerilen kontrol grafiğinin performansı Monte Carlo simülasyonu ile yapılmıştır. Çalışmada R IQCC paketi ve Faz II aşamasında $T^{2}$ değerlerinin hesaplanmasında T2.2 fonksiyonu kullanılmıştır.

Veljkovic (2019) tarafından yapılan çalışmada, normal dağılmayan kalite karakteristikleri izlemek amacıyla $X$ kontrol grafiğine dayalı bir yöntem önerilmiştir. Söz konusu çalışmalarda çeşitli hesaplamalarda $R$ paketlerinden Witkovsk ve Savin (2005) tarafından oluşturulan tdist paketi, Gastwirth, Gel, Wallace Hui, Miao ve Noguchi (2015) tarafından 
oluşturulan lawstat paketi, Gross ve Ligges (2015) tarafından oluşturulan nortest paketi ve Meyer, Dimitriadou, Hornik, Weingessel ve Leisch (2014) tarafından oluşturulan e1071 paketi kullanılmıştır.

\section{Bulgular}

Yapılan çalışmada oluşturulan araştırma ölçeğine göre R programlama dilinin kalite kontrol grafiklerinin kullanımına yönelik 4 adet kitap ve 36 adet makalenin incelenmesi bir önceki bölümde yapılmış ve makalelerin içeriği ve R programlama dilinin araştırılan makalelerde nasıl kullanıldığı ile ilgili olarak özet bilgiler verilmiştir. Bu kapsamda incelenen makalelerin yıllara sair olarak dağılımı Grafik-2'de verilmiştir.

Grafik-2. R Programlama Dilinin Kontrol Grafiklerinde Kullanımına Yönelik Yapılan Akademik Çalışmaların Yıllara Göre Dağılım Grafiği

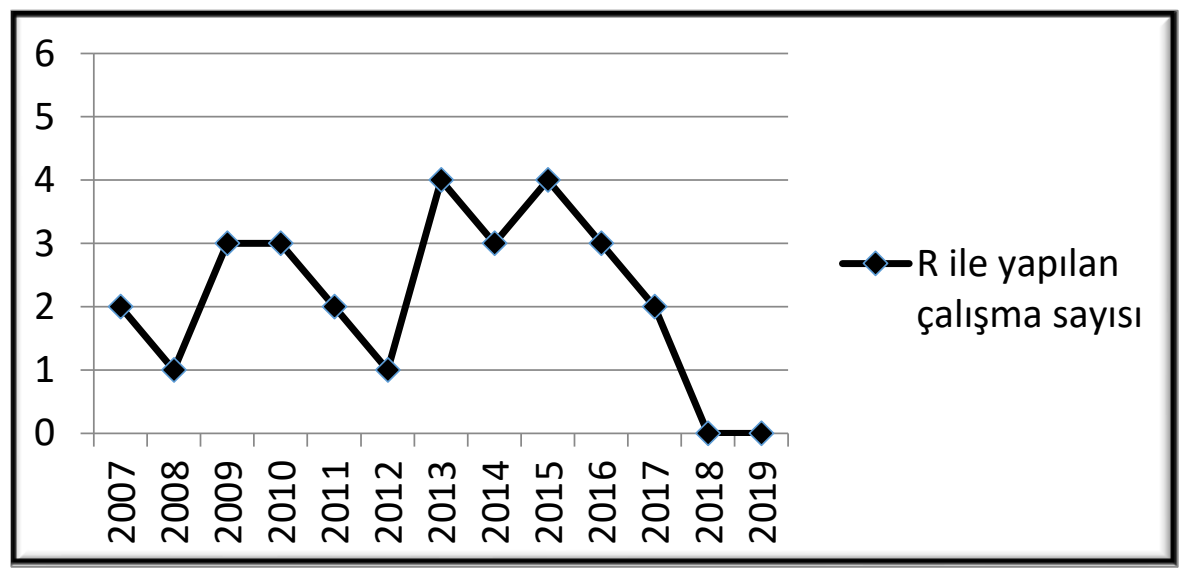

Grafik-2 incelendiğinde konu kapsamında yazılan makalelerin sayısında 2013-2016 yılları arasında bir artış olduğu, ancak daha sonraki dönemlerde ise daha az çalışmanın yapıldığı tespit edilmiştir.

Yapılan çalışmada makalelerin içerik analizi kapsamında oluşturulan ölçeğe göre incelenmesi neticesinde elde edilen sonuçlar ise Grafik$(3,10)$ 'de verilmiştir. 


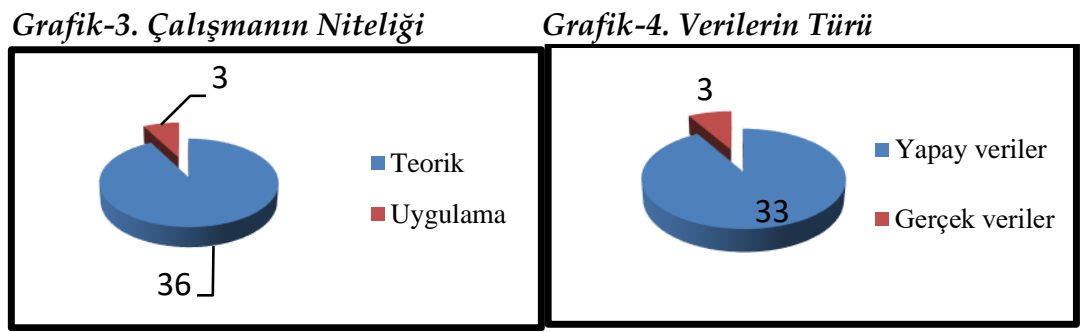

Grafik-3'de yeralan değerler incelendiğinde; R programlama dilinin kalite kontrol grafiklerinin kullanılmasına yönelik olarak yapılan çalışmalarının 36 adedinin teorik ve 3 adedinin ise hem teorik ve hem de gerçek üretim sürecinde uygulamalı olarak yapıldığı tespit edilmiştir. Gerçek üretim sürecinde yapılan kalite kontrol çabalarının uzun zaman alması, maliyetli olması ve gerekli izinlerin alınmasındaki zorluklar gibi nedenlerden dolayı akademik alanda yapılan çalışmaların teorik olarak yapılması tercih edilmektedir. Dolayısıyla gerçek uygulama alanında çalışmaların artırılmasının uygun olacağı değerlendirilmektedir.

Grafik-4'te yeralan değerler incelendiğinde; $\mathrm{R}$ programlama dilinin kalite kontrol grafiklerinin kullanılmasına yönelik olarak yapılan çalışmaların 33 adedinde yapay veriler ve 3 adedinde ise gerçek veriler kullanılmıştır. Bu kapsamda çalışmaların niteliğinde olduğu gibi gerçek verilerin bulunmasının zorluğundan dolayı çalışmaların sayısının az olduğu tespit edilmiştir. Dolayısıyla gerçek uygulama alanında çalışmaların artırılmasının uygun olacağı değerlendirilmektedir.

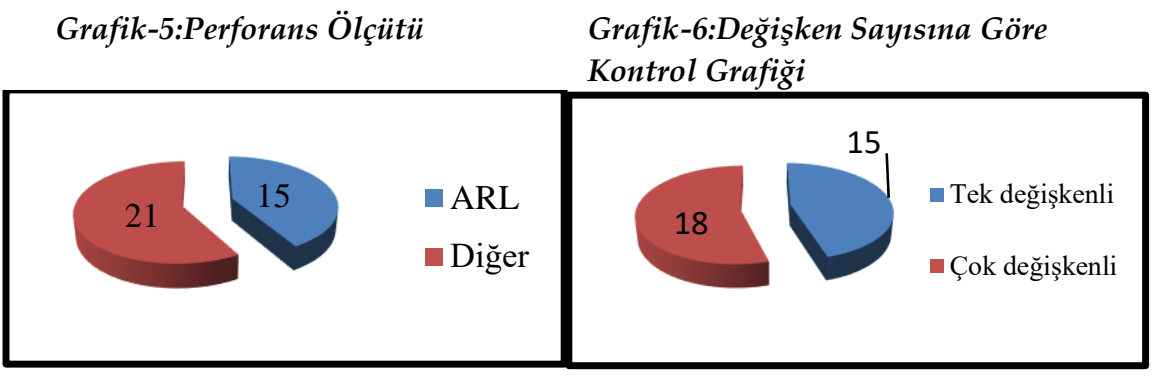

Grafik-5'te yeralan değerler incelendiğinde; $\mathrm{R}$ programlama dilinin kalite kontrol grafiklerinin kullanılmasına yönelik olarak yapılan 
çalışmalarda kontrol grafiklerinin performansının ölçümünde 15 adet makalede $A R L$ değerleri ile ilgili çalışmanın yapıldığı ve 21 adet makalede ise herhangi bir çalışmanın hatta kontrol grafiğinin performansı ile ilgili herhangi ölçünün olmadığı ve önerilmediği tespit edilmiştir. Ayrıca kontrol grafiklerinin performans ölçümü ile ilgili başka herhangi bir kritere de rastlanılmamıştır. Bu kapsamda sadece R programlama dilinin kullanılmasıyla ilgili değil $A R L$ ölçütünün alternatifi olacak şekilde başka performans ölçütlerin geliştirilmesinin uygun olacağı değerlendirilmektedir.

Grafik-6'da yer alan değerler incelendiğinde; R programlama dilinin kalite kontrol grafiklerinin kullanılmasına yönelik olarak yapılan çalışmalarda 15 adet makalede tek değişkenli kalite kontrol grafikleri ve 18 adet makalede ise çok değişkenli kalite kontrol grafikleri ile çalışmanın yapıldığ beraber birbiriyle ilişkili çok değişkenli yapılar ve süreçlerin ön plana çıktığı ve tek değişkenli yapıların halen devam ettiği ancak etkinliğinin azaldığ tespit edilmiştir.

Grafik-7: Çalışmalardaki R Paketleri Grafik-8:Kontrol Grafiğinin Tipi

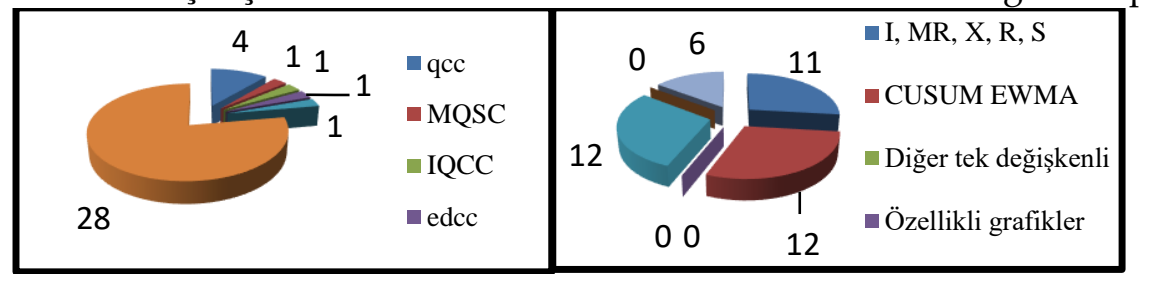

Grafik-7'de yer alan değerler incelendiğinde; $R$ programlama dilinin kalite kontrol grafiklerinin kullanılmasına yönelik olarak yapılan çalışmalarda, qcc paketi 4 adet çalışmada, MQSC paketi 1 adet çalışmada, IQCC paketi 1 adet çalışmada, edcc paketi 1 adet çalışmada, spcaiust paketi 1 adet çalışmada kullanıldığı tespit edilmiştir. Ayrıca R programında kalite grafikleri ile ilgili olarak oluşturulmuş paketlerin haricinde bazı işlemlerde 28 adet diğer $\mathrm{R}$ paketlerinde yer alan fonksiyonlarında kullanıldığ 1 tespit edilmiştir. Dolayısıyla genel kalite kontrol grafikleri ile ilgili paketlerin yanında diğer R paketlerinin de yoğun olarak kullanıldığı ve pratik uygulamalarda kullanılması için daha kolay ve görsellik içeren çalışmaların yapılmasına ihtiyaç duyulduğu düşünülmektedir. 
Grafik-8'de yer alan değerler incelendiğinde; R programlama dilinin kalite kontrol grafiklerinin kullanılmasına yönelik olarak yapılan çalışmalarda 11 adet yaygın olarak kullanılan tek değişkenli $I, M R, X, R, S$ kontrol grafiklerinin, 12 adet yaygın olarak kullanılan tek değişkenli CUSUM ve EWMA kontrol grafiklerinin, 12 adet çok değişkenli $T^{2}$, MCUSUM ve $M E W M A$ kontrol grafiklerinin ve 6 adet özel tip kontrol grafiklerinin kullanıldığı tespit edilmiştir. Dolayısıyla $\mathrm{R}$ paketlerinin bulanık ve özellikli tip kalite kontrol grafiklerinde kullanılmasına yönelik çalışmaların yapılabileceği değerlendirilmektedir.

Grafik-9. Verilerin Dağılımı Grafik-10. Parametrelerinin Bilinip Bilinmemesi

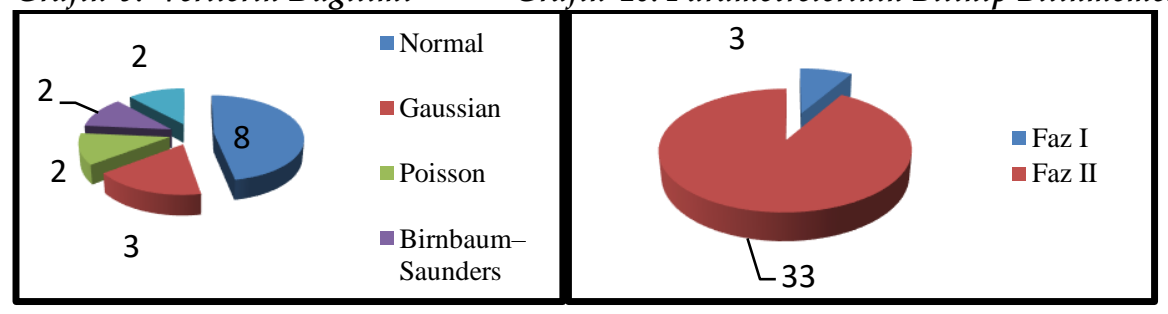

Grafik-9'da yer alan değerler incelendiğinde; R programlama dilinin kalite kontrol grafiklerinin kullanılmasına yönelik olarak yapılan çalışmalarda verilerin sekiz adet inakalede normal, üç adet makalede Gaussian, iki adet makalede Poisson, iki adet makalede Birnbaum-Saunders, iki adet makalede Conway-Maxwell-Poisson (C-M-P) dağıldığı ve geri kalan makaleler de ise verilerin dağılımının bilinmediği görülmüştür. Dolayısıyla kontrol grafiklerinin oluşturulmasında ağırlıklı olarak parametrik yöntemlerin kullanıldığı ancak diğer dağılımlarında kullanıldığı ve kullanılan dağılımlara uygun olarak $R$ paketlerinin ve bu paketlerde uygun fonksionların seçilmesi gerekmektedir.

Grafik-10'da yer alan değerler incelendiğinde; $R$ programlama dilinin kalite kontrol grafiklerinin kullanılmasına yönelik olarak yapılan çalışmalarda 33 adet çalışma da sürecin parametrelerinin bilindiği ve 3 adet çalışmada ise belli bir örneklem üzerinden hesaplanması gerektiği görülmüştür. Diğer bir deyişle yapılan çalışmaların 3 adedinin kontrol grafiklerinin Faz I aşaması ve 33 adedinin ise kontrol grafiklerinin Faz II aşaması ile ilgili olduğu tespit edilmiştir. Dolayısıyla günümüzde çoğunlukla süreçlerin parametrelerinin bilinmeyen süreçlerin ön plana çıktığı 
anlaşılmıştır. Ancak gerçek dünyada veya endüstrilerde süreçlerin parametreleri nadiren bilinir. Dolayısıyla konu ile ilgili olarak yapılan çalışmaların daha çok Faz I aşaması ile ilgili yapılmasının literature katkı açısından daha uygun olacağı değerlendirilmektedir.

\section{Sonuç ve Öneriler}

R programlama dili özellikle Avrupa'da ve Amerika'da bulunan istatistikçiler tarafından yoğunlukla tercih edilen programdır. Bu programlama dilinin kullanımı Türkiye'de de her geçen gün artmaktadır. R programlama dili, özellikle her türlü ekonometrik ve istatistik çalışmanın yanı sıra veri madenciliği, büyük veri analizi, simülasyon uygulamaları gibi birçok alanda kullanım imkanı sunmaktadır. $\mathrm{R}$ programlama dilinin kullanım alanlarından birisi de kalite kontrol grafikleridir. Yapılan çalışmada içerik analizine uygun olarak $\mathrm{R}$ programlama dilinin kalite kontrol grafiklerinin oluşturulmasında kullanımı araştırılmıştır. Araştırma kapsamına uygun olarak bir adet araştırma ölçeği oluşturulmuş ve genel ağda konu kapsaminda belirlenen anahtar kelimeler kullanılarak $\mathrm{R}$ programlama dilinin kalite kontrol grafiklerinin kullanıldığı kitaplar ve makalelerin olup olmadığı araştırılmıştır. Araştırma neticesinde; dört adet kitap, yetmiş üç adet makale ve 23 adet Web sitesi bulunmuştur. Ancak bulunan dokümanların ve Web sitelerinin incelenmesi neticesinde; konu ile ilgili dört adet kitabın ve 36 adet makalenin olduğu görülmüştür. Web sayfalarının akademik doküman olmamasından dolayı araştırma kapsamı dışında tutulmuştur. Çalışmanın sonucunda; (1) R programının kontrol grafiklerinde kullanımı ile ilgili olarak incelenen kitaplarda ve makalelerde teorik konulara ağırlık verildiği, uygulamalı konuların azınlıkta olduğu, (2) kalite kontrol grafiklerinin dizayn edilmesinde en çok $R$ paketlerinden qcc paketinin kullanıldığı, ancak diğer paketlerden de ihtiyaç duyulan fonksiyonların kullanıldığı, (3) yapılan uygulamalar ile teori geliştirmede ağırlıklı olarak çok değişkenli kontrol grafiklerinin kullanıldığı ve kullanılan kontrol grafiklerinden ise en çok Hotelling $T^{2}, M C U S U M$ ve MEWMA kontrol grafikleri ile uygulamaların yapıldığı, (4) kontrol grafiklerinin performansının ölçülmesinde ve performanslarının karşılaştırılmasında $A R L$ değerlerinin kullanıldığı, (5) kontrol grafikleri ile yapılan uygulamalarda ağırlıklı olarak 
yapay verilerin kullanıldığı, (6) simülasyon çalışmalarında Monte Carlo simülasyon yönteminin tercih edildiği ve bunların haricinde (7) çeşitli durumlar için önerilen çok çeşitli kontrol grafiğinin literatürde yer aldığı sonucuna ulaşılmıştır.

Ayrıca yukarıda oluşturulan ölçeğe göre tespit edilen hususlara ek olarak belirlenen konular ile gelecek dönemlerde araştırmacılar tarafindan yapılabilecek hususlar ile ilgili görüş ve öneriler aşağıya maddeler halinde çıkarılmıştır.

Tespit edilen hususlara ek olarak;

- R programını kalite kontrol grafiklerini kullanacak çalışanların ayn anda programlama dili, istatistik bilgisi ve kalite konusunda mühendislik bilgisine sahip olması gerektiği,

- R paketinin kalite kontrol grafiklerinde kullanılmasına yönelik teorik bilginin verilmesi, paket oluşturma ve kodlama faaliyetlerinin çok, uygulamaların ise az olduğu,

- $\quad \mathrm{R}$ paketinin diğer paket programlara (MINITAB, SPSS) göre literatürde kalite kontrol grafiklerinin dizaynında ve endüstride kullanımında daha az kullanıldığı,

- R paketlerinin hazırlanma hızı, R paketlerinin kullanılarak akademik çalışma yapma hızı ile gerçek üretim süreçlerinde kalite kontrolü çalışmaları yapma hızından daha süratli artmakta olduğu,

- R ortamının ağırlıklı olarak kalite kontrol grafiklerinde ileri düzeyde kullanıldığı görülmüştür.

Gelecek dönemlerde;

- R paketinin kalite yönetiminin diğer alanlarında da (Örneğin, altı sigma yaklaşımında) kullanıldığ̣ görülmüştür. Bu kapsamda bu konu ile ilgili olarak gelecek dönemlerde içerik analizi çalışmaları yapılabilir.

- R paketinin kullanılmasıla ilgili olarak teorik bilgileri kapsayan Türkçe bir kitap yazılabilir ve yerli literatüre katkı yapılabilir.

- Kalite kontrol grafikleri ile ilgili kullanıcı özellikle üretim sürecinde çalışanlar için kullanıcı dostu bir arayüz yaratılabilir.

- Yerli literatürde uygulamaya yönelik akademik çalışmalara ağırlık verilebilir. 


\title{
EXTENDED ABSTRACT
}

\section{Content Analysis about Usage of R Programming Language in Quality Control Charts}

\author{
Kenan Orçanlı \\ National Defence University
}

Although there are various methods that help improve quality in statistical process control, quality control charts are considered to be the most important methods available. The superiority of these charts compared to other methods is that they are easy to use, to design and visually understandable. Observations related to the quality characteristics determined in the quality control charts are generally followed by the creation of package programs such as SPSS, MINITAB, STATA or programming languages such as MATLAB, $\mathrm{C}++$. Recently, however, it has been determined that the use of $\mathrm{R}$ programs in the creation of quality control charts, the detection of uncontrolled signals in these charts, in the diagnosis of errors and similar areas is rapidly becoming widespread and a lot of studies are conducted in foreign literature. In this context, it was aimed to make a research about the use of $\mathrm{R}$ program in quality control charts. In this way, it is considered that this study will contribute to the quality control employees and the domestic and foreign literature. In this study, four books and thirty-six articles were examined according to content analysis method according to seven criteria.

According to Li and Çavuşgil (1995), there are three basic approaches in the literature to collect existing information in a field or a subject and to draw conclusions by organizing the collected information. These approaches are delphi method, content analysis and meta-analysis methods. In this study, content analysis method, which is a systematic, reproducible technique, in which some words of a text are summarized with smaller content categories is used with coding based on certain rules.

As a result of the study; 
- In the books and articles examined in relation to the use of the $\mathrm{R}$ program in control charts, theoretical issues are emphasized, applied issues are in the minority,

- Most of the R packages used in the design of quality control charts is qcc package,

- Mainly used control graphs are multivariate control graphs in theory development and applications, and most commonly used control charts were Hotelling T2, MCUSUM and MEWMA control charts, and

- Control charts were measured using $A R L$,

- Mainly used artificial data in applications with control charts,

- Monte Carlo simulation method is preferred in simulation studies,

- It is concluded that a wide variety of control charts suggested for various situations are included in the literature.

In addition to the issues identified;

- The employees who will use the R program quality control graphs must have engineering knowledge about programming language, statistics and quality at the same time,

- Giving theoretical information about the use of $\mathrm{R}$ package in quality control graphs, package creation and coding activities are very high and applications are low,

- $\mathrm{R}$ package is less used than other package programs (MINI$\mathrm{TAB}, \mathrm{SPSS}$ ) in the design of quality control graphics in the literature and used in industry.

- $\quad$ The speed of the preparation of $R$ packages is increasing faster than the speed of performing $R$ packages using academic packages and quality control in real production processes,

- It is seen that R environment is mainly used in advanced level in quality control graphics.

Also in the future period;

- The R package has also been used in other areas of quality management (for example, the six sigma approach). In this context, content analysis studies can be carried out in the future. 
- A Turkish book containing theoretical information about the use of the $\mathrm{R}$ package can be written and contributed to the domestic literature.

- A user-friendly interface can be created with regard to quality control graphics, especially for those working in the production process.

- Academic studies aimed at practice in the domestic literature can be emphasized.

\section{Kaynakça / References}

Alfaro, E., Alfaro, J. L., Gámez, M. ve García, N. (2009). A boosting approach for understanding out-of-control signals in multivariate control charts. International Journal of Production Research, 47(24), 6821-6834.

Alfaro, E., Gamez, M. ve Garcia, N. (2006). Adabag: Implements AdaBoost.M1 and bagging [online]. $\mathrm{R}$ package version 1.0. https://cran.r-project.org/web/packages/available_packages_by_name.html, Erişim tarihi:01 Haziran 2019.

Alfaro, J. L. ve Ortega, J. F. (2009). A comparison of robust alternatives to Hotelling's $T^{2}$ control chart. Journal of Applied Statistics, 36(12), 1385-1396.

Andrejıvá, M. ve Kımáková, Z. (2012). The open source software "R" in the statistical quality control. International Journal of Engineering, 3, 17-25.

Arslan, İ. (2017). R ile istatistiksel programlama. İstanbul: Pusula Yayınları.

Assareh, H., Noorossana, R. ve Mengersen, K. L. (2013). Bayesian change point estimation in Poisson-based control charts. Journal of Industrial Engineering International. 2(2), 12-23.

Bell, R. C., Jones-Farmer, L. A. ve Billor, N. (2014). A distribution-free multivariate Phase I location control chart for subgrouped data from elliptical distributions. Technometrics, 56(4), 528-538.

Birgören, B. (2015). İstatistiksel kalite kontrolü. Ankara: Nobel Akademik Yayıncilik.

Bush, H. M., Chongfuangprinya, P., Chen, V. C. P., Sukchotrat, T. ve Kim, S. B. (2010). Nonparametric multivariate control charts based on a linkage ranking algorithm. Quality and Reliability Engineering International, 26, 663-675.

Büyüköztürk, Ş. ve diğerleri (2010). Bilimsel araştırma yöntemleri, 7. Baskı, Ankara: PEGEM Akademi. 
Cano, E. L., Moguerza Mariano J. M. ve Corcoba, P. (2015). Quality control with $R$ an ISO standards approach. New York Dordrecht, Springer Cham Heidelberg, London.

Marchant, C., Leiva, V., Cysneiros, F. J. A. ve Liu, S. (2018). Robust multivariate control charts based on Birnbaum-Saunders distributions. Journal of Statistical Computation and Simulation, 88(1), 182-202.

Capizzi, G. ve Masarotto, G. (2011). A least angle regression control chart for multidimensional data. Technometrics, 53(3), 285-296.

Chananet, C., Sukparungsee, S. ve Areepon, Y. (2014). The ARL of EWMA chart for monitoring ZINB model using Markov chain approach. International Journal of Applied Physics and Mathematics, 4(4). 236-239.

Chiang, J. Y., Liob, Y. L. ve Tsaic, T. R. (2017). MEWMA control chart and process capability indices for simple linear profiles with within-profile autocorrelation. Quality and Reliability Engineering International, 33, 1083-1094.

Capizzi, G. ve Masarotto, G. (2016). Efficient control chart calibration by simulated stochastic approximation. IIE Transactions, 48(1), 57-65.

Cohen, L., Manion, L. ve Morrison, K. (2007). Research methods in education (6th Edition), London: Routledge Falmer.

Capizzi, G. ve Masarotto, G. (2010). Evaluation of the run-length distribution for a combined Shewhart-EWMA control chart. Stat, 20, 23-33.

Cano, E. L. (2011). An introduction to $R$ for quality control. Newyork: Universidad Rey Juan Carlos Publication.

Farkas, K. (2015). CUSUM Anomaly Detection. Measurement Lab. 1-25.

Gandy, A. ve Kvaløy, J. T. (2013). Guaranteed conditional performance of control charts via bootstrap methods. Scandinavian Journal of Statistics, 40, 647-668.

Gastwirth, J. L., Gel, Y. R., Wallace Hui, W. L., Miao, W. ve Noguchi, K. (2015). Lawstat: Tools for Biostatistics, Public Policy, and Law. R package version 2.5. https://cran.r-project.org/web/packages/ available_packages_by_name.html, Erişim tarihi: 01 Haziran 2019.

Gross, J. ve Ligges, U. (2015). Nortest: Tests for Normality. R package version 1.0-3. https://cran.r-project.org/web/packages/available_packages_by_name.html, Erişim tarihi: 01 Haziran 2019.

Giner-Bosch, V., Cabanos, C. ve Debón-Aucejo, A. (2016). On the use of statistical process control in monitoring mortality: An application to European countries. Estadística Española, 58(191) 265-275. 
Henning, E., Maia, M. T., Walter, O. M. F. C., Konrath, A. C. ve Alves, C. C. (2014) Application of Hotelling's $T^{2}$ control chart for a machining process of the inside diameter of a steel cylinder. GEPROS (Gestão da Produção, Operações e Sistemas, Bauru), 9(2), 155-167.

Höhle M. (2007). Surveillance: An R package for the monitoring of infectious diseases. Comput Stat, 22, 571-582. https://cran.r-project.org/web/packages/available_packages_by_name.html, Erişim tarihi: 01 Haziran 2019.

Işığıçok, E. (2012). Toplam kalite yönetimi bakış açısıyla istatistiksel kalite kontrol, Bursa: Ezgi Yayınevi.

Kuvattana, S., Busababodhin, P., Areepong, Y. ve Sukparungsee, S. (2016). Bivariate copulas on the exponentially weighted moving average control chart. Journal of Science Technology, 38 (5), 569-574.

Knoth, S. (2015). Run length quantiles of EWMA control charts monitoring normal mean or/and variance. International Journal of Production Research, 53(15), 4629-4647.

Konrath, A. C., Walter, O. M. F. C., Henning, E., Alves, C. C. ve Samohyl, R. W. (2013). Applications in teaching statistical quality control with different R interfaces. 2013 IEEE Global Engineering Education Conference (EDUCON), 146.

Lee, Y. H. ve Von Davier, A. A. (2013). Monitoring scale scores over time via quality control charts, model-based approaches and time series techniques. Psychometrika, 78(3), 557-575.

Leiva, V., Hernandez, H. ve Riquelme, M. (2006). A new package for the Birnbaum-Saunders distribution. $R$ News, 6(4), 35-40.

Li, T. ve Çavuşgil, S. T. (1995). A classification and assessment of research streams in international marketing. International Business Review, 4(3), 251-77.

Lio, Y. L. ve Park, C. (2010). A bootstrap control chart for inverse Gaussian percentiles. Journal of Statistical Computation and Simulation, 80(3), 287299.

Lio, Y. L. ve Park, C. (2008). Research a bootstrap control chart for birnbaumsaunders percentiles. Quality and Reliability Engineeing International, 24, 585-600.

McCarthy, D. J., Campbell, K. R., Lun, A. T. L. ve Wills, Q. F. (2017). Scater: Pre-processing, quality control, normalization and visualization of single-cell RNA-seq data in R. Bioinformatics, 33(8), 1179-1186. 
Mcneil, A. ve Ulman, S. (2013) QRMlib: Provides R-language code to examine Quantitative Risk Management concepts. R package version 1.4.5.1, https://cran.r-project.org/web/packages/ available_packages_by_name.html Erişim tarihi: 01 Haziran 2019.

Meyer, D., Dimitriadou, E., Hornik, K., Weingessel, A. ve Leisch, F. (2014). e1071: Misc Functions of the Department of Statistics, TU Wien. R package version 1.6-4. https://cran.r-project.org/web/packages/available_packages_by_name.html Erişim tarihi: 01 Haziran 2019.

Morton, A., Gatton, M., Tong, E. B. A, Clements, A. (2007). New control chart methods for monitoring MROs in Hospitals. Australian Infection Control, 12(1), 16-18.

Orçanlı, K. (2017). Çok değişkenli kontrol grafikleri ve yapay sinir ă̆ları yöntemi ile döküm sanayinde bir istatistiksel süreç kontrolü uygulaması. Yayımlanmamış Doktora Tezi, Atatürk Üniversitesi, Sosyal Bilimler Enstitüsü, Erzurum.

Orçanlı, K., Oktay, E. ve Birgören, B. (2015). Çok değişkenli kontrol kartları örüntü tanıma literatüründe bir araştırma. Sosyal Bilimler Araştırma Dergisi, 4(2), 23-42.

Öztürk, A. (2009). Kalite yönetimi ve planlaması. Bursa:Ekin Yayınları.

Phaladiganon, P., Kim, S. B., Chen, V. C. P., Baek, J. G. ve Park, S. K. (2011). Bootstrap-based $T^{2}$ multivariate control charts, Communications in Statistics-Simulation and Computation, 40(5), 645-662.

Plummer, M., Best, N., Cowles, K. ve Vines, K. (2010). The Coda package: Output Analysis and Diagnostics for MCMC, R Package Version 0.13-2. https://cran.r-project.org/web/packages/available__ packages _by_name.html Erişim tarihi: 01 Haziran 2019.

Rashid, M., Riaz, M. ve Does, R. J. M. M. (2012). Efficient power computation for $\mathrm{R}$ out of M runs rules schemes. Comput Stat, 28, 667-681.

Radziwill, N. (2015). X-Bar/R Control Charts, http://qualityand innovation.com, Erişim tarihi:01 Haziran 2019.

Qiu, P. (2014). Introduction to statistical process control, Boca Raton:Chapman \& Hall/CRC.

Saghir, A. ve Lin, Z. (2013). Control chart for monitoring multivariate COMPoisson attributes, Journal of Applied Statistics, 41(1), 200-214.

Santos-Fernández, E. (2012). Multivariate statistical quality control using $R$. Springer New York Heidelberg Dordrecht London.

Satman, M. H. (2018). R ile programlama. İstanbul:Türkmen Kitapevi. 
Scrucca, L. (2004). qcc: An R package for quality control charting and statistical process control. $R$ News 4(1),1117.

Santos-Fernandez, E. (2013). MSQC: Multivariate Statistical Quality Control. $\mathrm{R}$ package version 1.0.0, https://cran.r-project.org/web-/packages/available_packages_by_name.html Erişim tarihi: 01 Haziran 2019.

Sündüs, D. A. (2015). A real application on economic design of control charts with R-edcc package. The International Journal of Engineering and Science (IJES), 4(10), 54-65.

Vargas, M., Alfaro, J. L. ve Mondéjar, J. (2009). On the run length of a statespace control chart for multivariate autocorrelated data. Communications Simulation and Compuin Statistics Tation, 38(9), 1823-1833.

Veljkovic, K., Elfaghihe, H. ve Jevremovic, V. (2015). Economic statistical design of Xbar control chart for non-normal symmetric distribution of quality characteristic. The International Conference 13th Serbian Mathematical Congress-2014, 29(10), 2325-2338.

Variyath, A. M. ve Vattathoor, J. (2013). Robust control charts for monitoring process mean of Phase-I multivariate individual observations. Journal of Quality and Reliability Engineering, 1-14.

Veljkovic, K. (2019). Xbar control chart for non-normal symmetric Metodolo`ski zvezki, 13(2), 87-100.

Vives-Mestres, M., Daunis-i-Estadella, J. ve Martin-Fernandez, J.A. (2015). Signal interpretation in Hotelling's $T^{2}$ control chart for compositional data. IIE Transactions, 48(7), 661-672.

Varadhan, R. ve Gilbert, P. (2009). BB: An R package for solving a large system of nonlinear equations and for optimizing a high-dimensional nonlinear objective function. Journal of Statistical Software, 32, 1-26.

Van den Boogaart, G. K., Tolosana, R. ve Bren M. (2014). Compositions: Compositional Data Analysis, R package version 1.40-1. https://cran.r-project.org/web/packages/ available_packages_by_name.html

Wheeler, B. (2008). SuppDists: Supplementary distributions, R package version 1.1-2, https://cran.r-project.org/web/packages/ available_packages_by_name.html, Erişim tarihi:01 Haziran 2019.

Witkovsk, V. ve Savin, A. (2005). Tdist: Distribution of a linear combination of independent Student's $\mathrm{t}$-variables. $\mathrm{R}$ package version 0.1.1. https://cran.r-project.org/web/packages/available by_name.html Erişim tarihi: 01 Haziran 2019. 
$\mathrm{Zu}, \mathrm{W}$. ve Park, C. (2013). An R package for the economic design of the control chart. Journal of Statistical Software, 52(9), 1-24.

\section{Kaynakça Bilgisi / Citation Information}

Orçanlı, K. (2019). Kalite kontrol grafiklerinde R programlama dilinin kullanımı ile ilgili içerik analizi. OPUS-Uluslararası Toplum Araştırmaları Dergisi, 13(19), 1390-1429. DOI: 10.26466/opus.589423 